\title{
SEISMIC PERFORMANCE OF AN UNREINFORCED MASONRY BUILDING: AN EXPERIMENTAL INVESTIGATION
}

\author{
Jitendra K Bothara ${ }^{1}$, Rajesh P Dhakal ${ }^{2}$, John B Mander ${ }^{3}$
}

\begin{abstract}
This paper presents the results of an experimental investigation carried out to investigate the seismic performance of a two storey brick masonry house with one room in each floor. A half-scale building constructed using single wythe clay brick masonry laid in cement sand mortar and a conventional timber floor and timber roof clad with clay tiles was tested under earthquake ground motions on a shaking table, first in the longitudinal direction and then in the transverse direction. In each direction, the building was subjected to different ground motions with gradually increasing intensity. Dynamic properties of the system were assessed through white noise tests after each ground motion. The building suffered increasing levels of damage as the excitations became more severe. The damage ranged from cracking to global/local rocking of different piers and partial out-of-plane failure of the walls. Nevertheless, the building did not collapse under base excitations with PGA up to $0.8 \mathrm{~g}$. General behaviour of the tested building model during the tests is discussed, and fragility curves are developed for unreinforced masonry buildings based on the experimental results.
\end{abstract}

Keywords: Unreinforced masonry, seismic performance, shaking table test, fragility curves

\section{Introduction}

Unreinforced masonry (URM) is the most common form of building construction in many countries. In developing countries, such houses are commonly conceived by the owners without following any engineering design principles and are constructed by local masons without following code-recommended practice. Even in developed countries, any URM buildings existing nowadays were most likely designed and constructed several decades ago when the seismic design philosophy was in its infancy. As a result, most URM buildings fall well short on the yardstick of modern seismic design requirements.

URM buildings have suffered severe damage, in many occasions leading to collapse, during medium to large earthquake shaking; thereby resulting in significant loss of life and property. Increasing interest in the last few decades has resulted in many experimental tests on URM sub-assemblages [1-5] and on complete URM buildings [6-12]. These studies have provided significantly valuable insights into seismic performance of URM buildings. However, many characteristics of URM buildings, such as seismic performance of URM gable walls and clay tiles as roofing materials, are yet to be fully understood. The lack of understanding of URM buildings is further compounded by diversity in its construction, its non-engineered nature and non-standard design [13-15], regional differences in construction materials and techniques used, and age of the buildings.

To understand the dynamic behaviour and to develop simplified fragility curves of a general class of URM buildings that are representative of houses in New Zealand, a one-half scale model of a two-storey brick house with flexible floor and roof has been constructed and tested on a shaking table under simulated earthquake ground excitation [16]. The building was slightly eccentric in terms of strength and stiffness. The experiments were conducted with progressively increasing degree of shaking in order to classify status of damage and

\footnotetext{
${ }^{1}$ Senior Seismic Engineer, Beca Carter Hollings \& Ferner Ltd, Wellington, NZ, jitendra.bothara@beca.com

${ }^{2}$ Assoc Professor, Department of Civil and Natural Resources Engineering, University of Canterbury,

Christchurch, NZ, rajesh.dhakal@canterbury.ac.nz

${ }^{3}$ Professor, Department of Civil Engineering, Texas A \& M University, TX, USA, jmander@civil.tamu.edu
} 
response quantities such as damping, stiffness and displacement amplitudes. The model was first tested in the longitudinal direction and then in the transverse direction after minor repair. This paper discusses idealization of the prototype building and the basis of modelling and fabrication of the scaled model, along with the experimental procedures, observations and their interpretation.

\section{Design of the Model Building}

The tested building is a half-scale model of an existing two-storey URM building in Christchurch, NZ. Hence, it represents a typical unreinforced masonry house that was common in the last century in New Zealand. The layout of openings, door and windows were sized and located to be representative of a range of a typical construction practice. However, the roof type and roofing material was changed to enable the behaviour of gable walls and roofing clay tiles to be observed. Figure 1 presents the basic layout of the model building. Due to limitations in the capacities of the shaking table and the overhead crane and also to fit within the working height available in the laboratory, a length scale of $\mathrm{S}_{\mathrm{L}}=1 / 2$ was decided. This resulted in a $2.8 \mathrm{~m} \times 1.92 \mathrm{~m}$ footprint of the model, which had $1.34 \mathrm{~m}$ high first floor, $1.14 \mathrm{~m}$ high second floor and $0.85 \mathrm{~m}$ high roof with a pitch. The twin wythe cavity walls in the prototype building were replicated in the model with single wythe walls. The mortar thickness was kept $12 \mathrm{~mm}$ in average. The model was constructed with the same materials as the idealized prototype. By adopting constant acceleration similitude, constant stress and strain similitudes were also achieved. This led to the following scale factors: force scale, $\mathrm{S}_{\mathrm{F}}=$ $1 / 4$; frequency scale, $S_{\mathrm{f}}=\sqrt{ } 2=1.414$; time and velocity scale, $\mathrm{S}_{\mathrm{t}}=\mathrm{S}_{\mathrm{v}}=1 / \sqrt{ } 2=0.707$; and mass density scale $S_{\rho}=2$.

For the mass similitude, live loads were ignored as the reduced live load required by most building codes contributes less than $5-6 \%$ of the total mass in such type of buildings. To meet similitude requirements, a total of 4.2 tonnes of additional mass was added to the gable walls at the floor and eaves level. To load the long walls, additional masses were fixed to the floor joist and roof ties. To load the short walls, platforms were constructed, one end of which was rigidly tied to the short wall and other end rested on sliding joints supported on floor joist or roof ties. The additional weights were attached to the floor or roof as close as possible to the walls to reduce any undue amplifying effect due to the diaphragms.

Note that load bearing masonry buildings with timber floor and roof structure are basically distributed mass systems where floor and roofs contribute less than $10-20 \%$ to the building mass. The additional mass, required for stress similitude, was lumped rather than uniformly distributed over the walls and floor. This may produce response mechanism different than in a real prototype and worsen the performance of the model during an excitation [11]. However, it is a basic limitation of constant acceleration modelling. In addition to it, as discussed earlier the twin wythe cavity walls were replicated with single wythe full sized brick walls. It would give appropriate in-plane shear stress and stiffness. However, because full-scale bricks were used for construction of the walls, consequent reduction in the out-of-plane moment of inertia would be just half, not $1 / 8$ as it would have been if half scale bricks were used. It will give much higher out-of-plane flexural stiffness and strength of walls. This is another limitation of this experimental work.

\section{Model Fabrication and Instrumentation}

The model was built with only one room at each floor level. This was to reduce construction complications, but was considered sufficient to study the dynamic behaviour of masonry buildings. The model was slightly eccentric in strength and stiffness due the opening locations and sizes of piers in the opposite walls. 


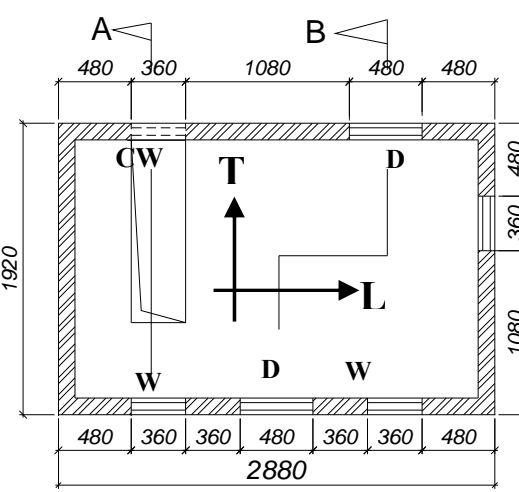

A B

Ground Floor Plan

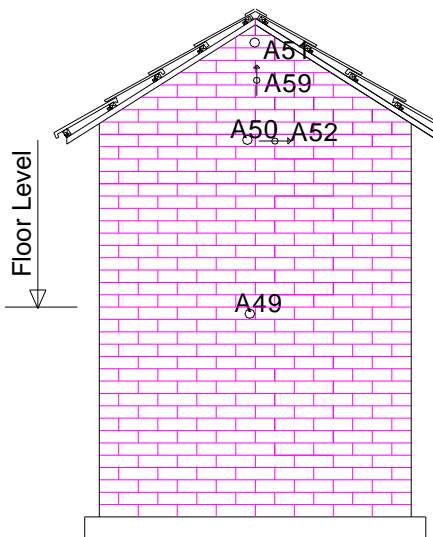

Side Solid Wall
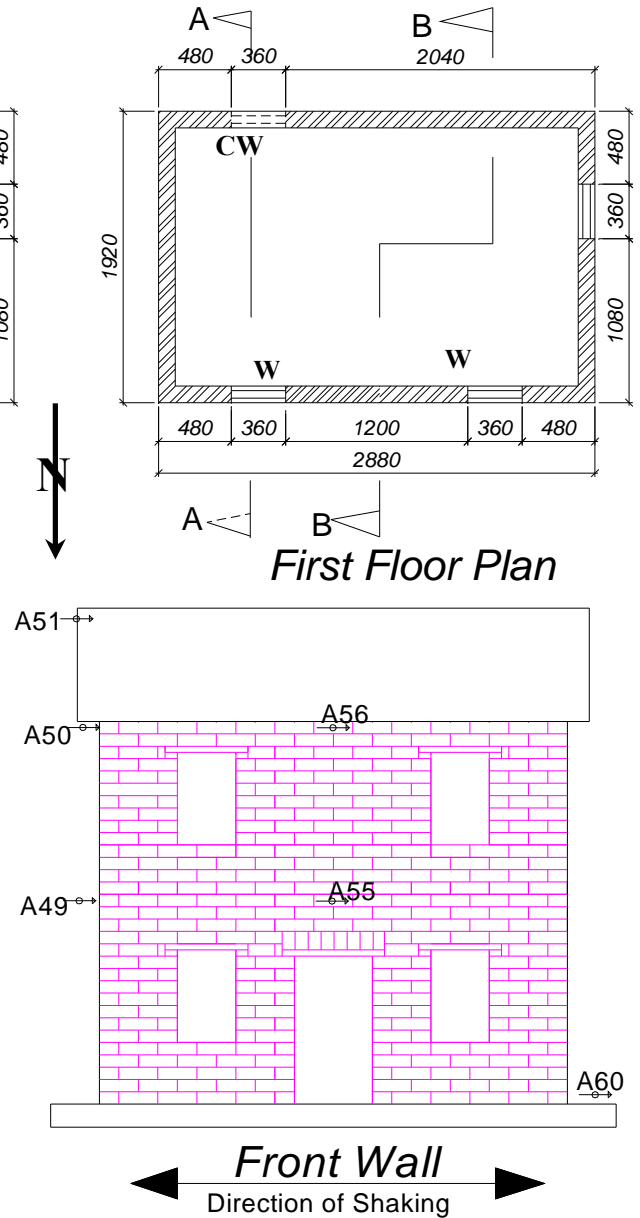

Direction of Shaking

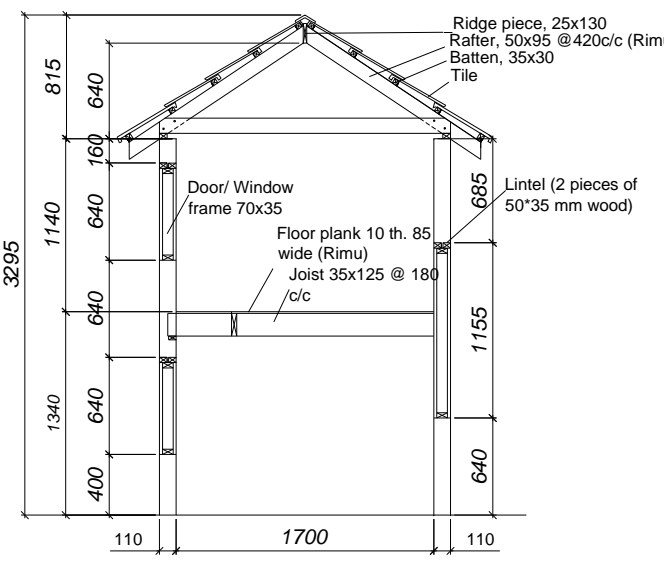

Section A-A

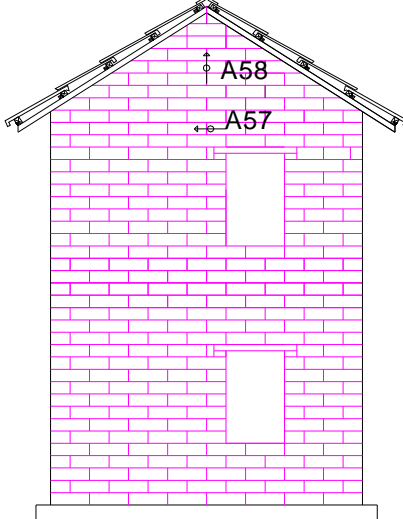

Side Window Wall

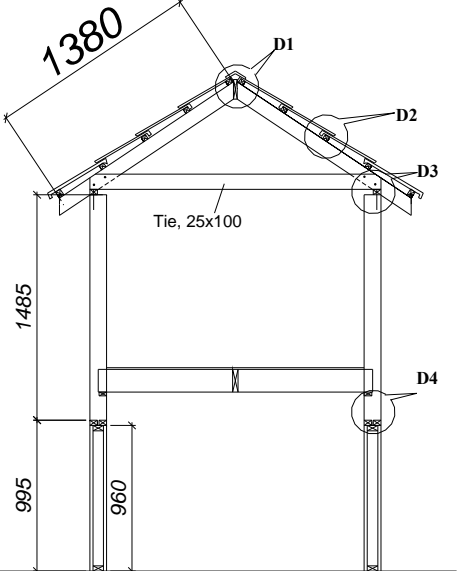

Section $B-B$

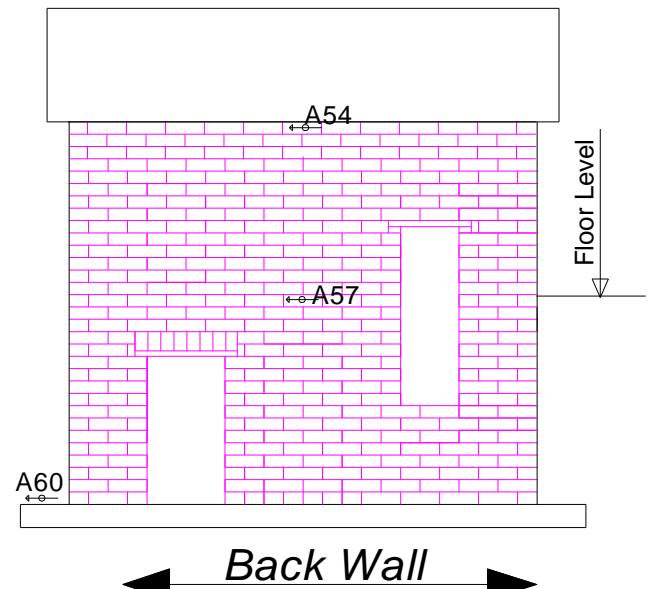

Back Wall

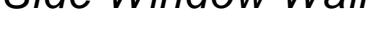

Figure 1: Plan and elevation of the model ( $N$ shows the north with respect to the model orientation when tested in Longitudinal direction, elevations show location of accelerometers when the model was tested in longitudinal direction) 


\section{Construction}

In this experimental work recycled full size wire cut bricks typical of early 1930s', commonly known as "seventy series" in New Zealand, were used. Based on customary building practices in early last century, a mortar mix of 1:1:6 (cement: lime: sand) was adopted. Nevertheless, the mortar examined in some URM buildings in New Zealand looked much weaker than 1:1:6; presumably due to ageing, or lack of quality control during the construction. When constructing walls, recommended practices such as soaking of bricks in water, dry mixing of mortar before adding water were followed.

Door and window frames were constructed of timber sections. To span the openings, timber lintels were provided with a bearing of $75 \mathrm{~mm}$ on the wall. The floor was constructed of $10 \mathrm{~mm}$ thick tongue and groove flooring nailed to timber joists which were nailed to wooden wall plates laid on the longitudinal walls. The portable pitched roof was constructed of timber to accommodate around 2 tonnes of additional mass. It led to somewhat stiffer and stronger roof than what was required. Both floor and roof structures were structurally separated from the transverse wall as in common practice. To observe the relative performance of different roofing systems, half of the tiles were alternatively tied down to the purlins and the rest were placed untied on one slope; and on the other slope all tiles were tied down to the purlins. After testing the model in the longitudinal direction, the gable walls were reconstructed.

\section{Material properties}

During construction of the model building, comprehensive material tests were conducted to track mechanical properties of the materials. Bricks were tested for compression and moisture absorption, and compression tests were also conducted on mortar cubes. Similarly, masonry prisms were tested to evaluate the masonry's strengths in compression, flexural bond and shear. The mortar cubes and masonry prisms were constructed from different layers of brickwork and at different time lag (after adding water to the dry mortar mixture) to track their effect on the strengths. Average values of the mechanical properties measured from these tests are presented in Table 1. Among the different parameters considered, time lag had the most noticeable influence on the mortar compressive strength, which reduced up to $35 \%$ in two and half hours. However, its effect on the properties of the masonry prism could not be ascertained. Note that these strengths are likely to be higher than the strengths of materials taken from existing masonry buildings.

Table 1: Average material properties

\begin{tabular}{|c|c|c|c|c|}
\hline Material & Test type & Test result & CoV & Remarks \\
\hline \multirow{3}{*}{ Brick } & Compressive & $26.6 \mathrm{MPa}$ & $17 \%$ & \\
\cline { 2 - 5 } & Initial Rate of absorption (IRA) & $63.6 \mathrm{gram}$ & $7.4 \%$ & \\
\hline Mortar cubes & Compressive & $7.6 \mathrm{MPa}$ & $10.6 \%$ & \\
\hline Masonry Prism & Compressive & $16.2 \mathrm{MPa}$ & $19.7 \%$ & At strain 0.0035 \\
\cline { 2 - 5 } & Young's Modulus, E & $6100 \mathrm{MPa}$ & $45.2 \%$ & At strain 0.0016 \\
\cline { 2 - 5 } & Shear Strength & $\tau_{\mathrm{o}}=0.93 \mathrm{MPa}$ & $38.6 \%$ & \\
\cline { 2 - 5 } & & $\Phi=44.4^{0}$ & $13.4 \%$ & \\
\cline { 2 - 5 } & Flexural bond & $0.42 \mathrm{MPa}$ & $35 \%$ & \\
\cline { 2 - 5 } & Split Bond & $0.41 \mathrm{MPa}$ & $38 \%$ & \\
\cline { 2 - 5 } & & & & \\
\hline
\end{tabular}

\section{Instrumentation}

A total of 61 and 41 channels of instruments were employed during testing in the longitudinal and transverse directions, respectively. Accelerometers and linear potentiometers were employed at the floor, eaves and gable levels in both out-of-plane and in-plane walls to capture the response of the model during the dynamic excitations. A total of 13 analogue and 
unidirectional accelerometers were used during the two test series. The locations of accelerometers used during the shaking table test in the longitudinal direction are also indicated in Figure 1. Similarly, 48 and 28 linear potentiometers were attached to the model building during the tests in the longitudinal and transverse directions, respectively. These potentiometers were employed to measure crack opening at the rocking base, shear deformations in the piers, sliding between the floor/roof and the walls, and movement of the model base slab in the direction of shaking. Apart from those used inside the building to measure the sliding between the floor/roof and walls, most of these potentiometers can be seen in Figure 2.

\section{Experimental Setup and Loading Protocol}

The testing program was basically aimed at two objectives: i) identification of dynamic characteristics; and ii) investigation of seismic behaviour of URM buildings. For identification of dynamic properties, the model building was subjected to several white-noise excitations. To investigate the model building's response to strong shaking, it was subjected to frequency-scaled earthquake ground motions in the longitudinal and transverse directions. A view of the model building on the shaking table is shown in Figure 2.

The base excitations for the longitudinal and transverse shakings comprised of: (i) acceleration record from the Lincoln School Tunnel site in California during the Taft Earthquake (July 21, 1952); (ii) NS component of RA01168 551 record from the Umbria March Earthquake (September 1997, Italy); (iii) NS component of the 1940 El-Centro Earthquake; (iv) SYLM949 record from the Northridge Earthquake (January 17, 1994); and (v) a record from Nahanni Earthquake (23 December 1985). Apart from the 1940 El-Centro record, all other records were scaled to different PGA values to represent varying levels of seismic severity. The 1940 El-Centro earthquake record $(\mathrm{PGA}=0.348 \mathrm{~g}$ ) was applied unaltered to represent a "design basis" earthquake in a moderate earthquake zone.

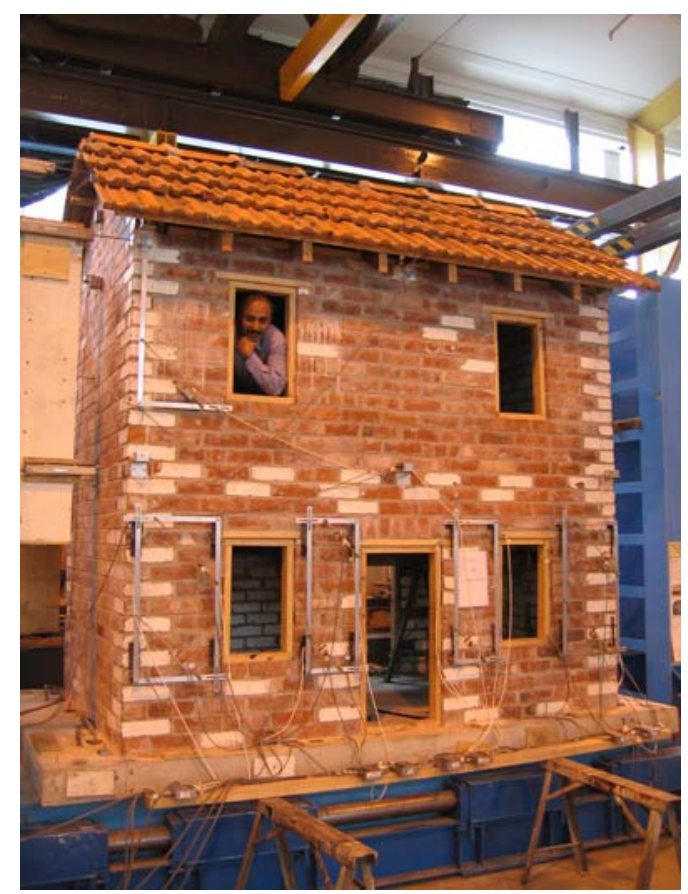

Figure 2: Model building on the shake table during testing in the longitudinal (E-W) direction 
Before starting the shakings in the longitudinal direction and after each earthquake record excitation in the transverse direction, white-noise tests were conducted to assess the dynamic characteristics of the model building. The white-noise excitation, which consisted of a wide band motion (0.1-30 Hz), was developed using a random function to acquire acceleration records which have approximately the same power spectrum over the frequency range. Tables $2 \mathrm{a}$ and $2 \mathrm{~b}$ present the complete sequence of excitations (including white-noise) and their scaled PGA values for the longitudinal and transverse directions, respectively. It can be seen that except for the El-Centro record in the longitudinal direction, all ground excitations were applied in a sequence of increasing severity (i.e. PGA). Through this loading protocol, the response of URM buildings to different levels of seismic hazard could be inferred, which is in principle similar to the multi-level seismic performance assessment (MSPA) concept [17] except that the rigorous probabilistic earthquake record selection process [18] was not followed.

The shaking table of University of Canterbury is driven by displacement input motion; so all the acceleration time histories were double integrated to obtain a target displacement time history. The time intervals of the input earthquake acceleration time histories were compressed by a factor of $1 / \sqrt{2}$ (i.e. multiplied by 0.707 ) to be consistent with the reduced scale of the model. To reduce the displacement and velocity demands on the shaking table which was limited to $\pm 120 \mathrm{~mm}$ and $240 \mathrm{~mm} / \mathrm{sec}$ respectively, low frequency components were filtered out from the acceleration time history.

Table 2a: Longitudinal shaking test sequence

\begin{tabular}{|c|l|c|l|l|}
\hline S. No. & \multicolumn{1}{|c|}{ Acceleration Record } & PGA (g) & \multicolumn{1}{c|}{ Code } & \multicolumn{1}{c|}{ Purpose } \\
\hline 1 & White noise & $0.02 \mathrm{~g}$ & Wn $(0.02 \mathrm{~g})$ & Study of dynamic characteristics \\
\hline 2 & White noise & $0.05 \mathrm{~g}$ & Wn $(0.05 \mathrm{~g})$ & Study of dynamic characteristics \\
\hline 3 & Taft 2721 & $0.2 \mathrm{~g}$ & Taft $(0.2 \mathrm{~g})$ & Moderate level earthquake \\
\hline 4 & Taft2721 & $0.3 \mathrm{~g}$ & Taft $(0.3 \mathrm{~g})$ & Moderate level earthquake \\
\hline 5 & Umbria March (RA01168 551) & $0.5 \mathrm{~g}$ & RA01168 551 $(0.5 \mathrm{~g})$ & Severe earthquake \\
\hline 6 & El-Centro & $0.348 \mathrm{~g}$ & EL40NSC & Moderate to severe earthquake \\
\hline
\end{tabular}

Table 2b: Transverse shaking test sequence

\begin{tabular}{|c|l|c|l|l|}
\hline S. No. & \multicolumn{1}{|c|}{ Acceleration Record } & PGA (g) & \multicolumn{1}{|c|}{ Code } & \multicolumn{1}{|c|}{ Purpose } \\
\hline 1 & White noise & $0.05 \mathrm{~g}$ & Wn $(0.05 \mathrm{~g})$ & Study of dynamic characteristics \\
\hline 2 & Taft 2721 & $0.2 \mathrm{~g}$ & Taft $(0.2 \mathrm{~g})$ & Moderate level earthquake \\
\hline 3 & White noise & $0.05 \mathrm{~g}$ & $\mathrm{Wn}(0.05 \mathrm{~g})$ & Study of dynamic characteristics \\
\hline 4 & Taft2721 & $0.3 \mathrm{~g}$ & Taft $(0.3 \mathrm{~g})$ & Moderate level earthquake \\
\hline 5 & White noise & $0.05 \mathrm{~g}$ & $\mathrm{Wn}(0.05 \mathrm{~g})$ & Study of dynamic characteristics \\
\hline 6 & White noise & $0.05 \mathrm{~g}$ & $\mathrm{Wn}(0.05 \mathrm{~g})$ & Study of dynamic characteristics \\
\hline 7 & El-Centro & $0.348 \mathrm{~g}$ & EL40NSC & Moderate to severe earthquake \\
\hline 8 & White noise & $0.05 \mathrm{~g}$ & $\mathrm{Wn}(0.05 \mathrm{~g})$ & Study of dynamic characteristics \\
\hline 9 & Umbria March (RA01168 551) & $0.5 \mathrm{~g}$ & RA01168 551(0.5g) & Severe earthquake \\
\hline 11 & Umbria March (RA01168 551) & $0.7 \mathrm{~g}$ & $\mathrm{RA} 01168551(0.7 \mathrm{~g})$ & Severe earthquake \\
\hline 12 & White noise & $0.05 \mathrm{~g}$ & Wn $(0.05 \mathrm{~g})$ & Study of dynamic characteristics \\
\hline 13 & North Ridge & $0.8 \mathrm{~g}$ & Sylm949 & Strong earthquake \\
\hline 15 & Nahanni & $0.8 \mathrm{~g}$ & Nahanni & Strong earthquake \\
\hline 16 & White noise & $0.05 \mathrm{~g}$ & Wn $(0.05 \mathrm{~g})$ & Study of dynamic characteristics \\
\hline
\end{tabular}

\section{Experimental Results: Longitudinal Excitations \\ Visual observations}


After each excitation the cracks were accurately mapped and plotted. The damage suffered by the tested URM building model after different shakings in the longitudinal direction is schematically shown in Figure 3. In the figure, it is evident that most cracks were concentrated in the first storey front wall (i.e. long in-plane wall). However, some cracks were observed in the transverse walls as well.

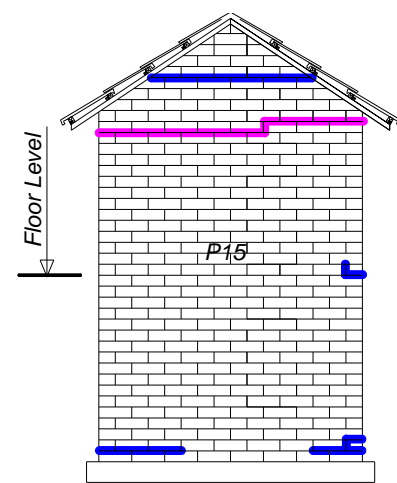

Side Solid Wall
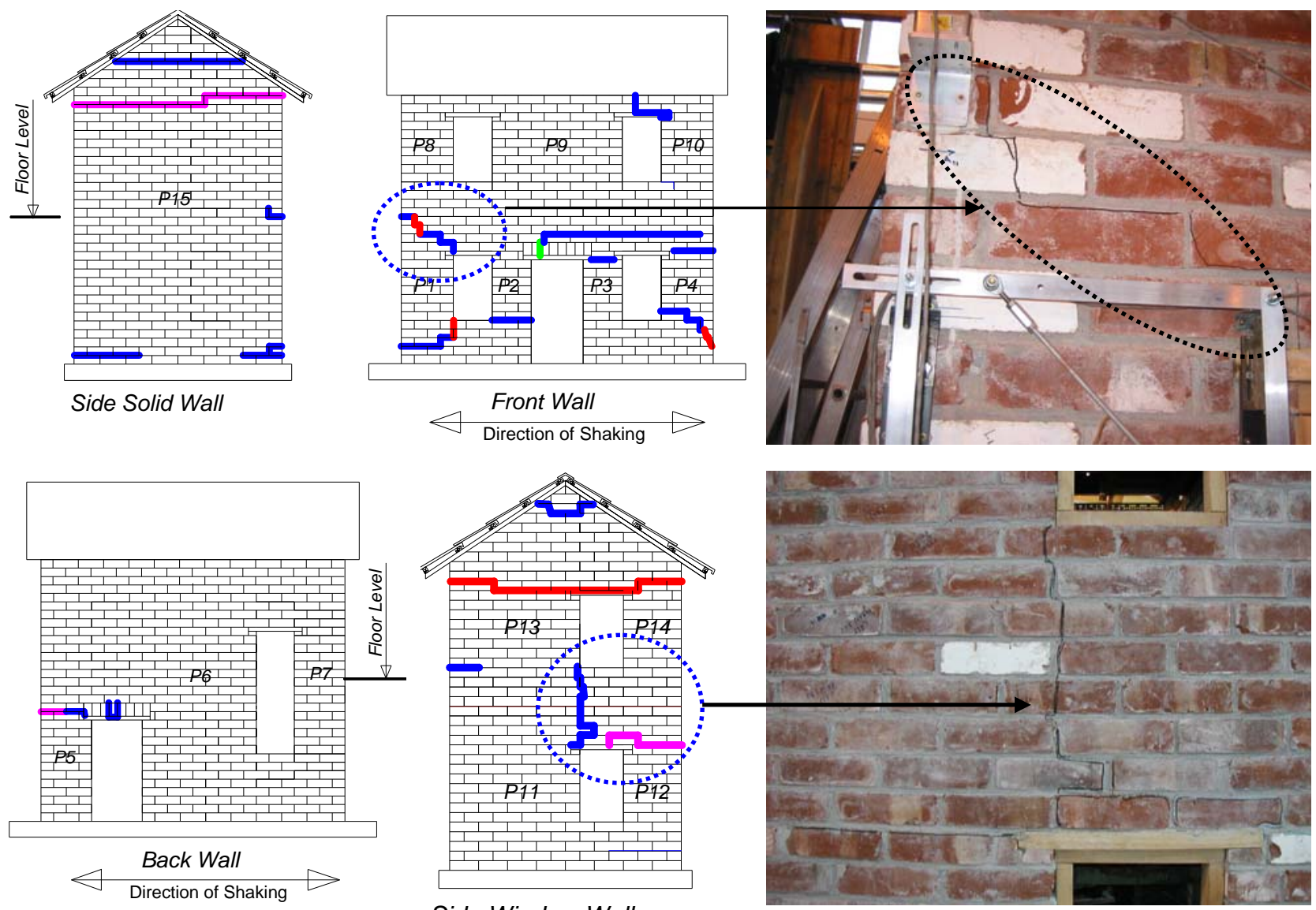

Side Window Wall
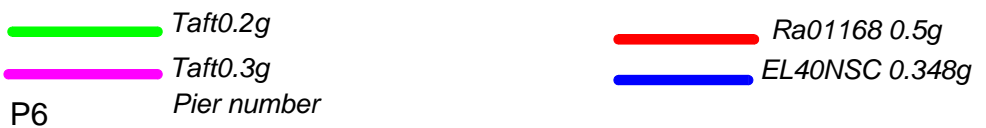

Figure 3: Crack propagation pattern during the Longitudinal shaking tests

A vertical crack was observed in the mortar joint of rowlock brick just above the front wall door after the Taft $(0.2 \mathrm{~g})$ shaking. The gable wall in the side solid wall cracked and started to rock at the eaves level during the Taft $(0.3 \mathrm{~g})$ excitation. During the RA01168 $(0.5 \mathrm{~g})$ shaking, horizontal cracks were observed in the bottom and the top of the front wall piers showing signs of rocking. During this excitation, the gable wall in the window side also cracked at its base. A compression crack was also observed in one of the corner piers. A vertical flexural crack developed in the spandrel beam in the transverse wall during the EL40NSC shaking. A horizontal crack was also observed just above the floor wall plate and brick interface in the front wall during this excitation. It should be noted that no instability of any part of the model (apart from the gable walls) was observed during the longitudinal shaking tests.

Response in time domain 
For each excitation in the longitudinal direction, the amplification factors are presented in Table 3. The amplification factors are ratio of peak response acceleration at a given location to the peak acceleration at the top of the base slab. Note that although the input records were scaled to $0.2,0.3$ and $0.5 \mathrm{~g}$ PGA, the peak acceleration measured at the base slab was slightly higher; and this difference was particularly significant for less severe excitations. It is clear from the table that the face wall (out-of-plane wall) in general and gable walls in particular suffered very high amplification up to 5.9, which forced the gable walls to crack and rock even during the smaller excitations. This observation is consistent with the well known fact that gable walls are highly vulnerable. Nonetheless, the gable walls did not topple because they were loosely tied to the roof with a chain to prevent from falling down.

Table: 3: Longitudinal shaking amplification factors

\begin{tabular}{|c|c|c|c|c|c|c|c|}
\hline \multirow{2}{*}{ Excitation } & \multicolumn{4}{|c|}{ Longitudinal Walls } & \multicolumn{3}{c|}{ Side Wall } \\
\cline { 2 - 6 } & \multicolumn{2}{|c|}{ Back Wall } & \multicolumn{2}{c|}{ Front Wall } & Floor & $\begin{array}{c}\text { Eaves } \\
\text { Level }\end{array}$ & $\begin{array}{c}\text { Top of } \\
\text { Gable } \\
\text { wall }\end{array}$ \\
\cline { 2 - 5 } & $\begin{array}{c}\text { Floor } \\
\text { Level }\end{array}$ & $\begin{array}{c}\text { Eaves } \\
\text { Level }\end{array}$ & $\begin{array}{c}\text { Floor } \\
\text { Level }\end{array}$ & $\begin{array}{c}\text { Eaves } \\
\text { Level }\end{array}$ & & & \\
\hline Wn $(0.05 \mathrm{~g})$ & 1.34 & 1.51 & 1.49 & 1.64 & 1.52 & 2.42 & 3.99 \\
\hline Taft $(0.2 \mathrm{~g})$ & 1.44 & 1.34 & 1.24 & 1.34 & 1.27 & 2.04 & 3.50 \\
\hline Taft $(0.3 \mathrm{~g})$ & 1.16 & 1.18 & 1.25 & 1.28 & 1.30 & 1.82 & 5.45 \\
\hline RA01168 $(0.5 \mathrm{~g})$ & 1.48 & 1.64 & 1.59 & 1.70 & 2.42 & 2.80 & 3.53 \\
\hline EL40NSC & 1.32 & 1.52 & 1.42 & 1.90 & 2.03 & 2.54 & 5.90 \\
\hline
\end{tabular}

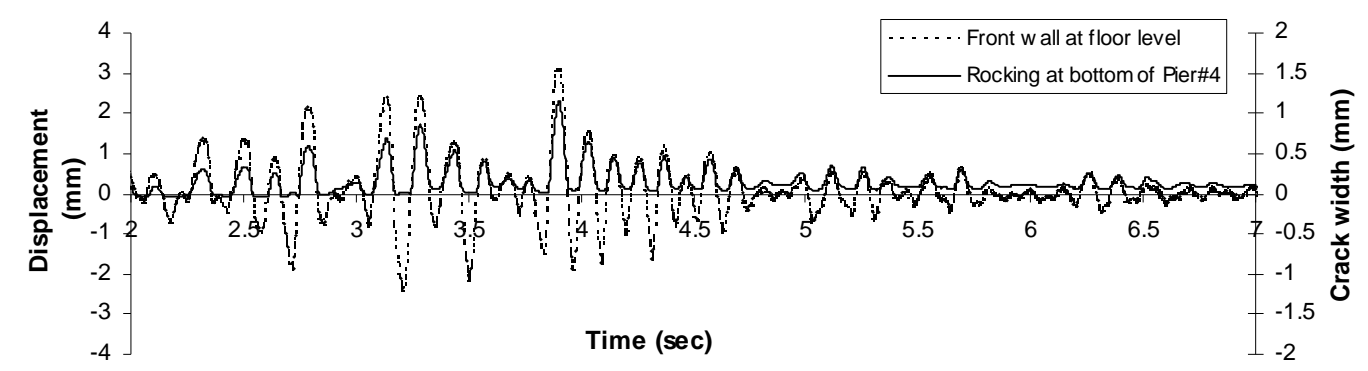

a) First floor level displacement versus rocking displacement of Pier\#4

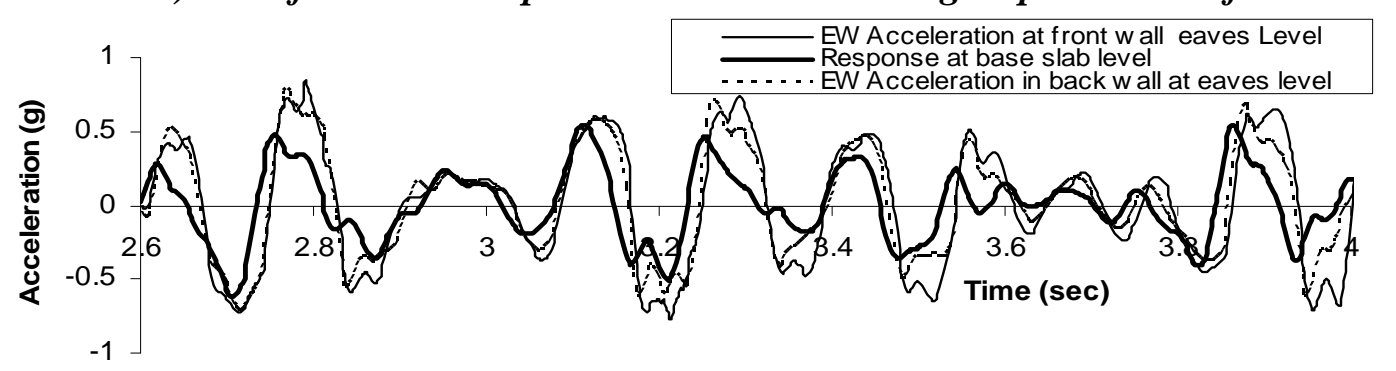

b) Response acceleration at Eaves level

Figure 4: Seismic response of the model to RA01168 (0.5g) excitation (longitudinal shaking)

During the Taft $(0.2 \mathrm{~g})$ excitation a consistent magnification of acceleration was observed almost without any phase difference. Though no cracking at the bottom or top of piers was visually observed after this shaking, the measured data indicated that the front wall piers had started rocking about the base. As shown in Figure 4a, the rocking (i.e. opening of the cracks at the base) of the front wall pier was significant (up to $1 \mathrm{~mm}$ ) during the RA01168 $(0.5 \mathrm{~g})$ excitation. More interestingly, the front wall pier rocking was in phase with the response of the front wall suggesting that the rocking at the base contributed to the eaveslevel displacement of the front wall. Note that although the front piers significantly rocked, 
nothing significant was observed in the back wall. The transient acceleration responses of the model building to the RA01168 $(0.5 \mathrm{~g})$ excitation measured at the base and eaves of the front and back walls are compared in Figure 4b. A phase shift between the input acceleration and the response acceleration can be seen in the figure, which indicates softening of the model.

Figure 5a presents the normalized forces at the two floor levels during the four excitations in the longitudinal direction. The floor level forces were computed by multiplying the measured acceleration by the tributary mass at that level, and the plotted coefficients are the normalized values with respect to the effective seismic mass of the model building. In uncracked state, the force pairs (at the two floors) are nearly equal. It contradicts with the code-recommended provision of triangular distribution of the floor level forces. However, with increasing damage in the bottom storey, a change in the lateral load distribution is evident in the figure.

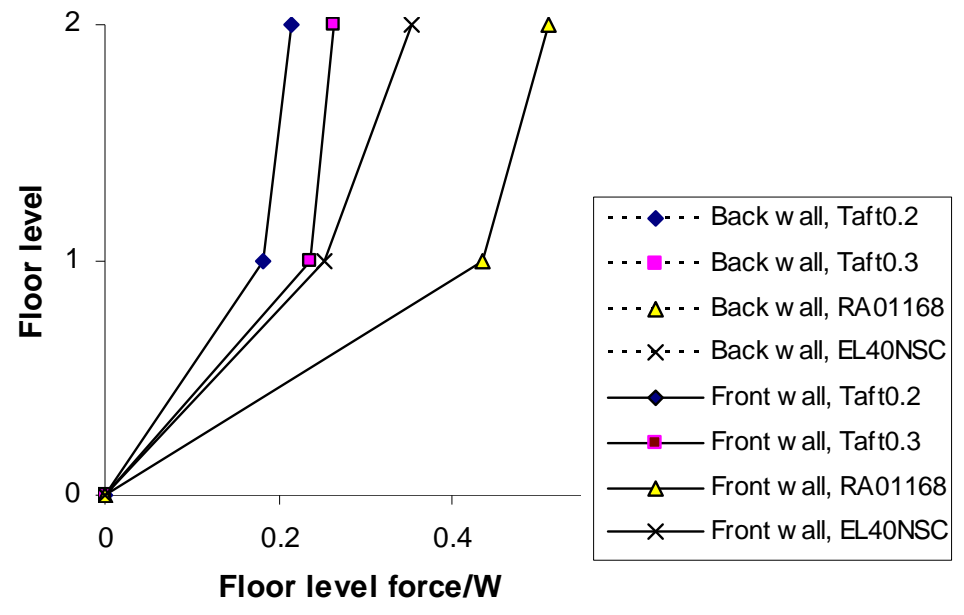

a) Lateral Force Pairs

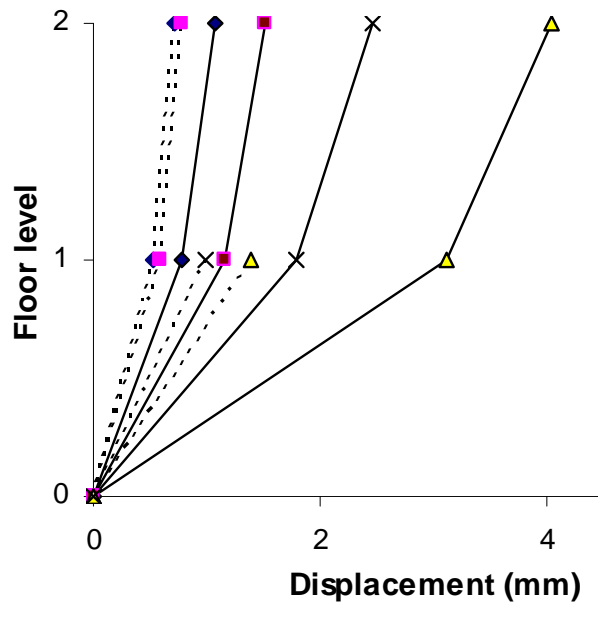

b) Measured Deflected shapes

Figure 5: Deflection and forces at the floor levels during the longitudinal shakings

Figure $5 \mathrm{~b}$ presents deflected shapes of the model during the four seismic excitations. Deflections measured at both the front and back walls are plotted in the figure. A rapid increase in deflection in the first storey front wall can be observed compared to the second storey. It is because most of the damage was concentrated in the first storey front wall. Moreover, throughout all excitations, the front wall deflected significantly more than the back wall and the rate of increase of deflection in the front wall also exceeded that in the back wall. These can be attributed to: (i) visibly more damage in the front wall (than in the back wall); and (ii) rocking of the front wall, which must have contributed to additional deflection.

Figures $6 \mathrm{a}$ and $6 \mathrm{~b}$ present average response acceleration-displacement curves for the Taft $(0.2 \mathrm{~g})$ and RA01168 (0.5g) excitations. A consistent increase in strength can be noticed after the first cracking if the two figures are compared. After initiation of cracking at the average response acceleration of $0.384 \mathrm{~g}$, the average response acceleration increased to $0.7 \mathrm{~g}$ during the RA01168 (0.5g) excitation. The maximum displacement observed at the first floor level was about $3 \mathrm{~mm}$ and that at the eaves level was $3.9 \mathrm{~mm}$ during this shaking. The figures show an increasing level of non-linearity and decreasing stiffness in the response of the model building with increasing excitation severity. After significant cracking during the RA01168 (0.5g) excitation, the acceleration-displacement plot is bilinear with the acceleration (i.e. capacity) degrading almost linearly because of the P- $\Delta$ effect. In order to see the response of the degrading system due to the first mode of vibration, the response data within the time window including the most intense shakings was narrowly filtered around the identified frequencies of the first mode [11, 19]. Moving average smoothing of the 
acceleration and displacement time history data was carried out to improve clarity of Figure $6 \mathrm{~b}$. The resulting plot of displacement versus the restoring force pertaining to the first mode is presented in Figure $6 \mathrm{c}$ for the same excitation. It is evident from the figure that with an increasing displacement, the stiffness (i.e. slope of the curve) decreases and the energy (i.e. area covered by the loop) increases; thereby indicating accumulation of damage.

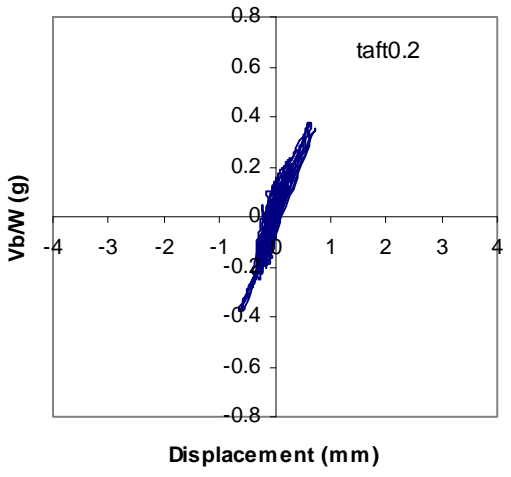

a) Taft (0.2g)

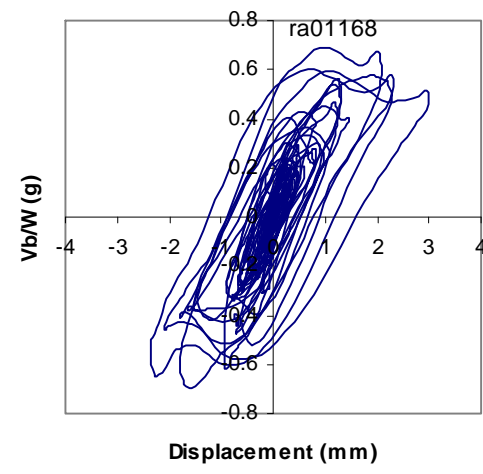

b) RA01168 (0.5g)

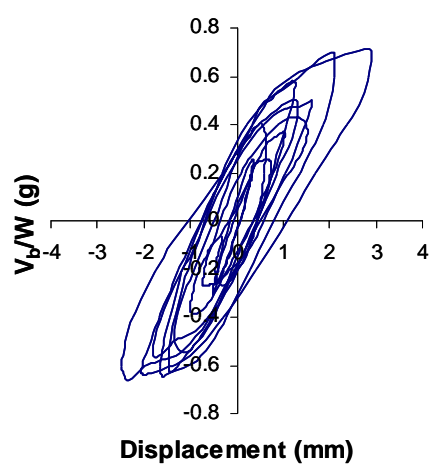

c) RA01168 (0.5g first mode)

Figure 6: Displacement versus average acceleration plots at the first floor level front wall (Longitudinal shaking)

The transverse acceleration response histories measured at the two side walls were compared during the different longitudinal excitations. It was found that a phase difference existed in the response acceleration time histories of the two walls, which suggests that the model was torsionally active. Based on the transverse acceleration measurements, the torsional response of the model was approximated. The inferred rotational acceleration histories of the model during the Taft $(0.2 \mathrm{~g})$ and RA01168 $(0.5 \mathrm{~g})$ excitations are plotted in Figures $7 \mathrm{a}$ and $7 \mathrm{~b}$, respectively. Although the normalized maximum acceleration decreased with increasing intensity of shaking, the rotational accelerations increased.

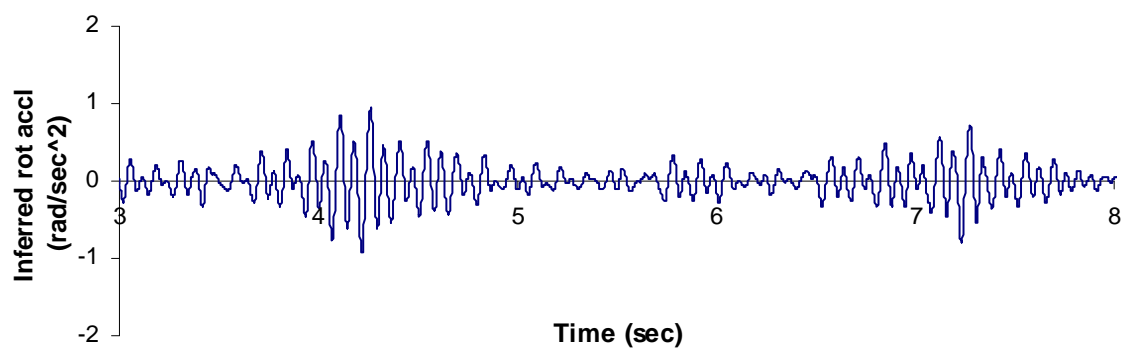

a) Inferred rotation during the Taft $(0.2 \mathrm{~g})$ excitation

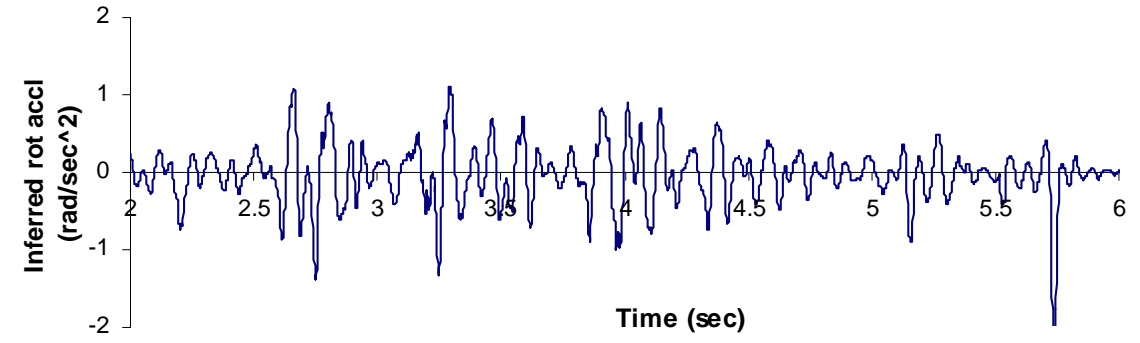

b) Inferred rotation during the RA01168 (0.5g) excitation

Figure 7: Inferred rotational acceleration of the model (Longitudinal shaking)

\section{Experimental Results: Transverse Excitations}




\section{Visual observations}

Figure 8 presents the damage suffered by the model during different excitations in the transverse direction. It should be noted that no instability of any part of the model was observed during the transverse shaking tests. From the figure, it is evident that most cracks concentrated in the second storey of the out-of-plane walls whereas the transverse window wall (in-plane wall) suffered extensive damage in both the first and second storey. Cracks were also observed in the bottom of the transverse solid wall. Cracks which had developed during earlier excitations in the longitudinal direction widened and extended during stronger excitations in this phase of testing.
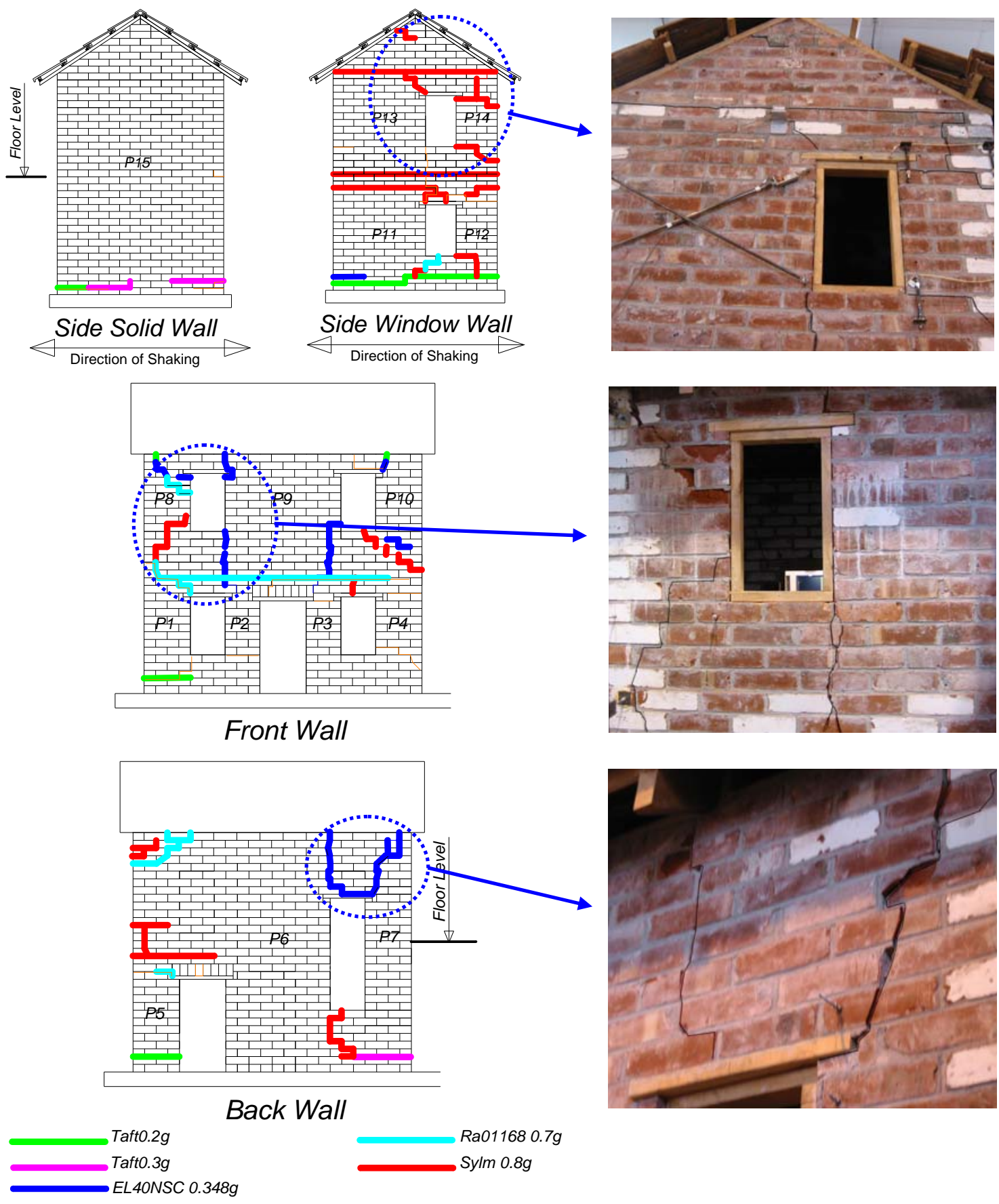

Figure 8: Crack propagation pattern during the Transverse shaking tests 
Small vertical cracks were observed above the second storey windows of the front wall after the Taft $(0.2 \mathrm{~g})$ excitation. During the Taft $(0.3 \mathrm{~g})$ excitation, cracks that developed during the Taft $(0.2 \mathrm{~g})$ excitation in the side solid wall further expanded and a few new cracks opened at the bottom of the side walls. During the EL40NSC excitation, extensive cracks developed in the out-of-plane walls. Vertical cracks developed along the line of jambs of the second storey openings in the front wall. Similar vertical or stair-step cracks developed above the long window of the back wall, practically isolating the wall from the in-plane walls in between. Severe cracking of the model caused dislocation of lintel timber pieces and permanent distortion of the opening frames were also observed.

During the RA01168 ( $0.7 \mathrm{~g})$ excitation, cracks that had previously developed widened, and some new cracks developed. A stair-step crack was observed just above the first storey window and in the pier of the second storey front wall. The front wall rocked about a horizontal crack along the mortar bed joint at the floor level during this shaking. During the SYLM949 $(0.8 \mathrm{~g})$ excitation, extensive cracks developed in both in-plane and out-of-plane walls. More stair-step cracks emerged in the spandrel beam of the front wall and along the mortar joint bed in the back wall. A full length horizontal crack developed along the bottom of the gable of the side window wall. Similar crack was also observed at the floor level of the side window wall. The vertical cracks in the spandrel beam and below the first storey window of the side window wall effectively divided the wall in two piers. During the Nahanni $(0.8 \mathrm{~g})$ excitation, the cracks further widened, however, no new cracks were observed.

No significant relative displacement between the floor and the supporting walls was observed. This is in contrast to the observed behavior in past earthquakes where relative movement between floor structure and walls were reported [14, 20]. The reasons for this lack of relative displacement between the floor and the supporting walls in the experiment could be: (i) the model was stable until the end of the testing without much distress in the first storey; and (ii) there was around 2 tonnes of mass on the first floor structure that mobilized friction between the floor wall plate and the supporting walls (note that this would not be available in this magnitude in real structures).

It is noteworthy that some of the unsecured roof tiles scattered badly and few of them slid off the roof slope during the RA01168 $(0.5 \mathrm{~g})$ excitation. As shown in Figure 9, these tiles slid off catastrophically during the RA01168 $(0.7 \mathrm{~g})$ and larger excitations. It is interesting to note the tile sliding started from the roof edge. However, tiles which were tied down with the roof structure did not move much and did not slide off the roof. These were in serviceable condition even at the end of the test, as can be seen in the figure.

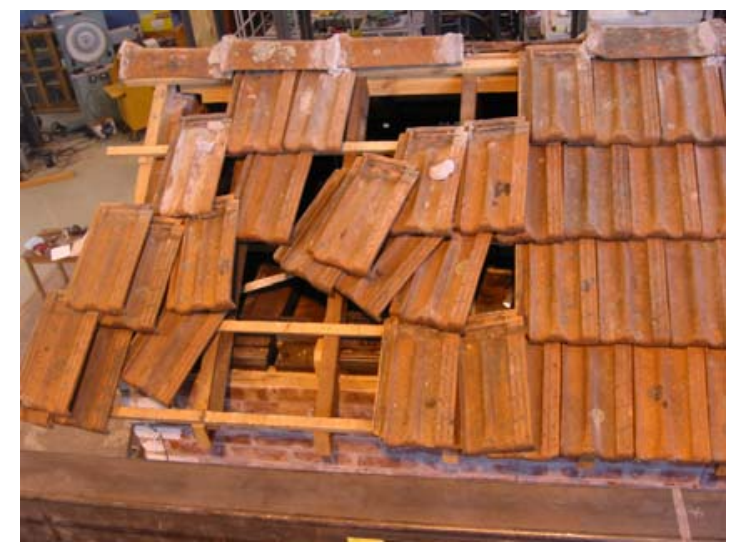

Figure 9: Scattering and falling of unsecured tiles (tied up tiles did not slide) 
For transverse direction too, the acquired data were processed to understand the behaviour of the model in time domain. For each excitation in the transverse direction, Table 4 presents the amplification factors computed based on the readings of all accelerometers oriented in the direction of shaking. The amplification factor ranged between 0.9 and 2.4. It is clear from the table that the out-of-plane wall, i.e. the front wall, experienced higher amplification up to 2.4, which diminished (especially at the eaves level) with increasing level of damage. In case of the in-plane walls the variation of the amplification factor with the damage was random. Due to higher in-plane stiffness the amplification factors are closer to unity (i.e. the response accelerations are closer to the base accelerations).

Table: 4: Transverse shaking amplification factors

\begin{tabular}{|c|c|c|c|c|c|c|}
\hline \multirow{3}{*}{ Excitation } & \multicolumn{3}{|c|}{ Longitudinal wall } & \multicolumn{3}{c|}{ Side walls } \\
\cline { 2 - 7 } & \multicolumn{2}{|c|}{ Front wall } & \multicolumn{2}{c|}{ Solid wall } & \multicolumn{2}{c|}{ Window wall } \\
\cline { 2 - 7 } & Floor level & Eaves level & Floor level & Eaves level & Floor level & Eaves level \\
\hline Taft $(0.2 \mathrm{~g})$ & 1.4 & 2.2 & 1.1 & 1.2 & 1.0 & 1.3 \\
\hline Taft $(0.3 \mathrm{~g})$ & 1.9 & 2.4 & 1.9 & 1.8 & 1.0 & 1.2 \\
\hline EL40NSC & 1.7 & 2.1 & 1.4 & 1.4 & 1.3 & 1.5 \\
\hline RA01168 $(0.5 \mathrm{~g})$ & 2.0 & 1.6 & 1.0 & 1.1 & 1.1 & 1.5 \\
\hline RA01168 $(0.7 \mathrm{~g})$ & 1.6 & 1.3 & 1.1 & 1.1 & 1.1 & 1.3 \\
\hline Sylm949 $(0.8 \mathrm{~g})$ & 1.2 & 1.1 & 1.0 & 1.3 & 0.9 & 1.1 \\
\hline Nahanni $(0.8 \mathrm{~g})$ & 1.5 & 1.3 & 1.1 & 1.1 & 1.0 & 1.2 \\
\hline
\end{tabular}

Figure 10a presents displacement of floor/roof level seismic mass during different transverse excitations. A rapid increase in displacement of the second storey floor level seismic mass center can be observed compared to the first storey. It is because the damage was more extensive in the second storey than in the first storey. Figure $10 \mathrm{~b}$ presents the normalized forces (computed as discussed earlier) at different floor levels during the transverse excitations. In uncracked or insignificantly cracked state, the forces in the two floors are nearly equal. However, with increasing damage in the second storey during the severer excitations, the force continuously decreased in the second storey and increased in the first storey. The second mode (as identified later in Figure 13) could be significantly contributing to the increase in the first floor force level during the higher damage levels.

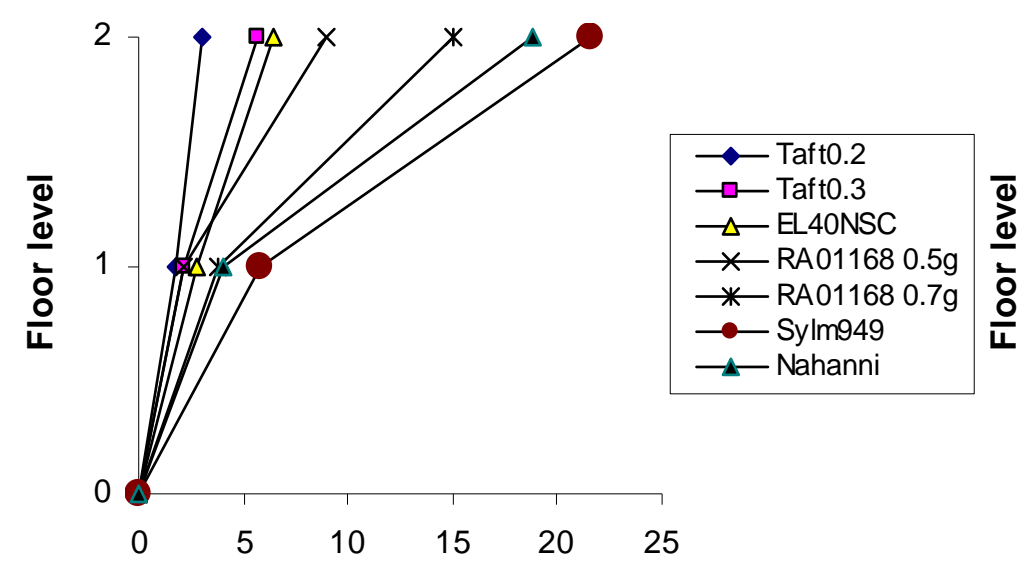

Displacement of seismic mass center $(\mathrm{mm})$

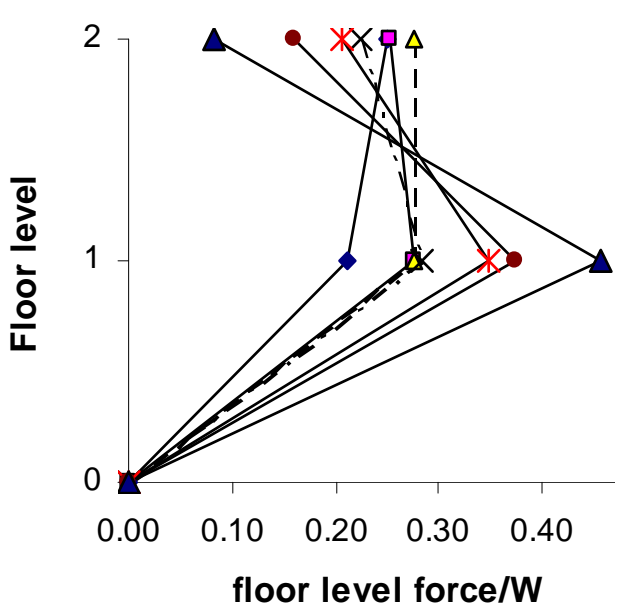

b) Lateral Force Pairs

a) Measured Deflected shapes

Figure 10: Deflection and forces at the floor levels during the Transverse shaking 
The instrumental data shows that the front wall cracked at the base of the second storey at an early stage of Taft $(0.2 \mathrm{~g})$ excitation. To explain the general features of the model response to different transverse excitations, the transient response of the model to the RA01168 $(0.7 \mathrm{~g})$ excitation is presented in Figure 11. A significant phase shift between the input base acceleration and response accelerations of different walls can be seen in Figure 11a. It indicates softening of the model and consequently different dynamic characteristics of the building components. The same is evident in Figure 11b. In this excitation, maximum out-of-plane displacement of the front wall was observed to be about $19 \mathrm{~mm}$. Figure 11c shows that the cracks at the bottom of the side window walls opened up to $4.2 \mathrm{~mm}$ which is consistent with the rocking displacement at the eaves level of the wall.

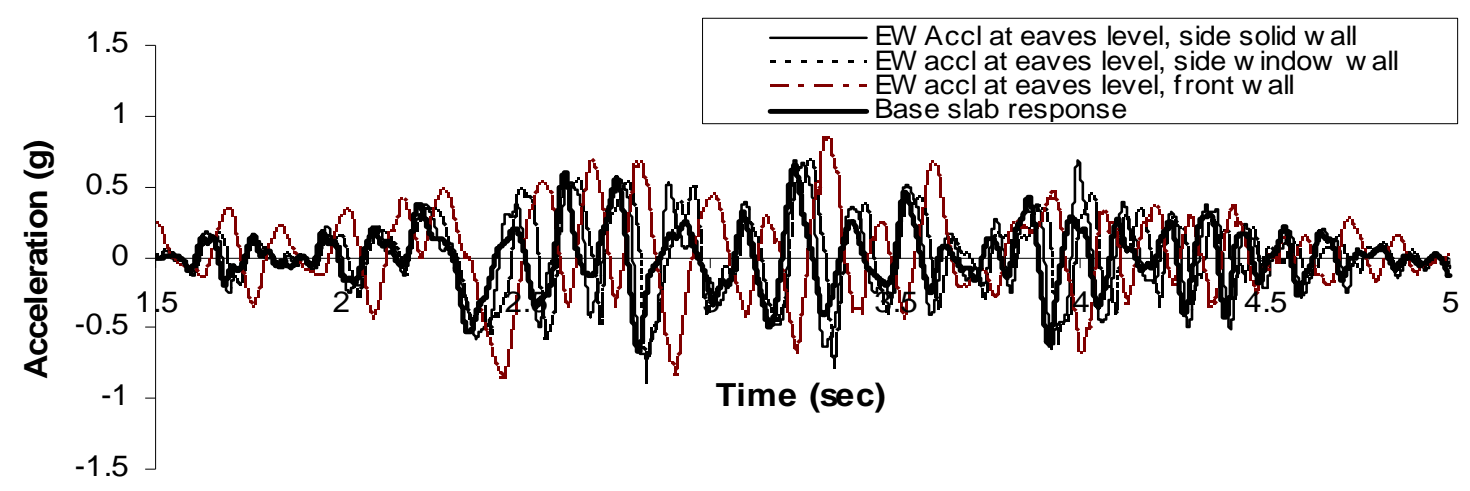

a) Response acceleration at Eaves level

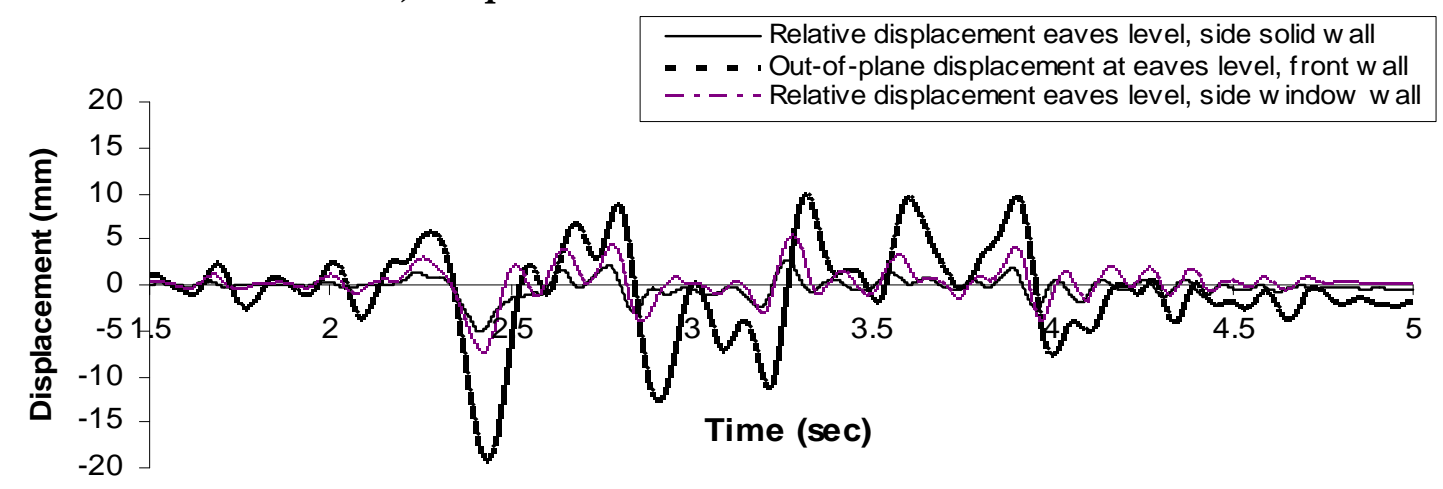

b) Displacement at Eaves level

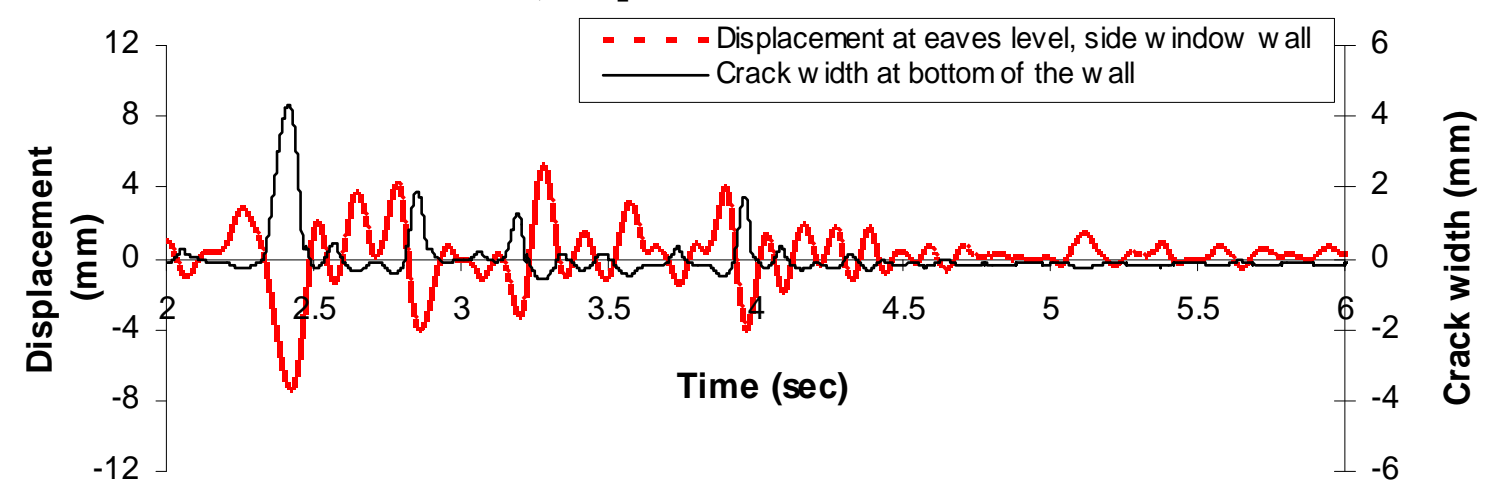

c) Eaves level deflection and crack opening at the bottom of the side window wall Figure 11: Seismic response of the model to RA01168 (0.7g) excitation (transverse shaking) 
As in the longitudinal shaking tests, a phase difference existed between the orthogonal acceleration responses of the front and back walls during the transverse shaking tests as well, which indicate that the model building was torsionally active. Figures $12 \mathrm{a}$ and $12 \mathrm{~b}$ plot the inferred rotational acceleration calculated from the in-plane response of the front and back walls for the Taft $(0.2 \mathrm{~g})$ and RA01168 (0.5g) excitations. As can be seen in these figures, the rotational acceleration increased with increasing intensity of shaking.

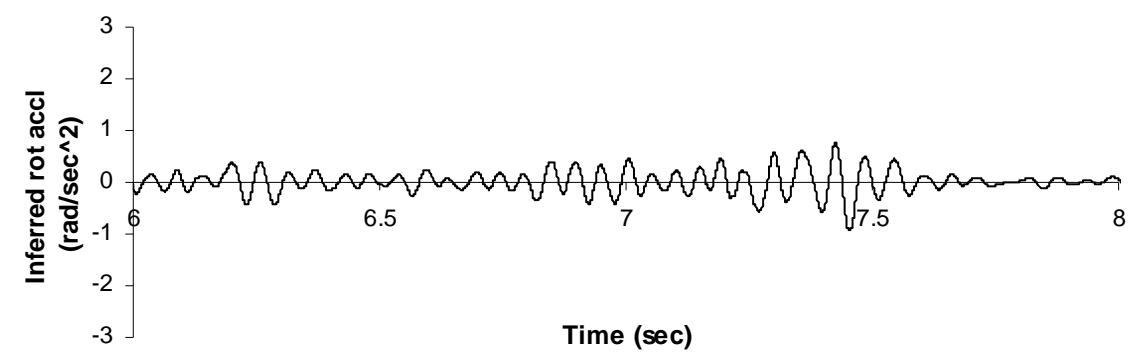

a) Inferred rotation during the Taft $(0.2 \mathrm{~g})$ excitation

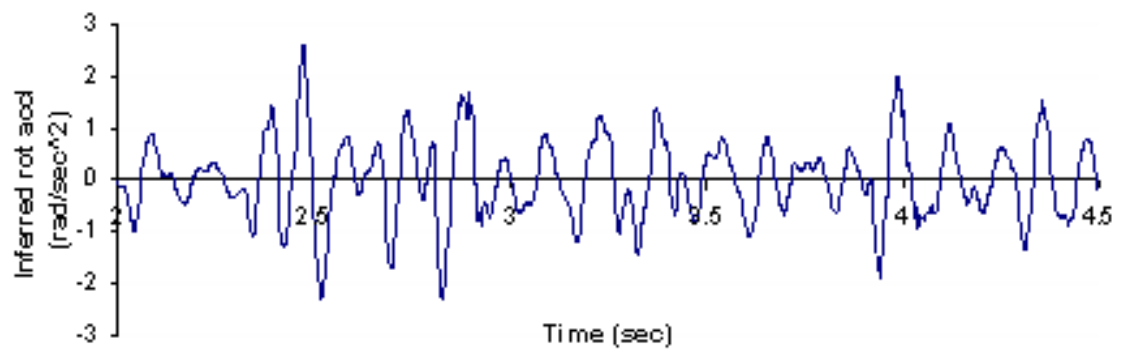

b) Inferred rotation during the $\mathrm{RA01168}(0.5 \mathrm{~g})$ excitation

Figure 12: Inferred rotational acceleration of the model (Transverse shaking)

\section{Frequency Domain Observations}

Dynamic properties of the model were evaluated from the response acceleration time histories measured during the shaking table tests. Transfer functions for the response of an instrumentation channel were calculated by normalizing the Fast Fourier Transfer (FFT) of the recorded response history by FFT of the input motion (in this case input acceleration at the base slab level). As an example, the transfer functions (up to $30 \mathrm{~Hz}$ frequency) of the eaves level acceleration response during different excitations in the two (longitudinal and transverse) directions are shown in Figures 13a and 13b, respectively. Intrinsic damping was calculated from the transfer function plots by applying half-power bandwidth method. The ratio of peaks in transfer functions for different degrees of freedom at a natural frequency is equal to the ratio of the corresponding mode shapes for that mode [21]. Hence, the mode shapes were calculated by taking the ratio of peaks in transfer function for different degrees of freedom at any particular natural frequency. The mode shapes were then normalized with respect to the maximum value. By taking only the first mode into account, the equivalent stiffness of the model is estimated using the following dynamic relation

$$
K=4 \pi^{2} M f^{2}
$$

where $M=$ seismic mass of building; and $f=$ measured frequency.

Figure 13 shows the results of frequency analysis conducted for the most significant period of all longitudinal excitations and the white noise excitations applied in the transverse direction. Table 5 presents damping and other dynamic characteristics of the model calculated from the measured responses during different excitations in the longitudinal direction. Both Table 5 and Figure 13a show a clear shift in frequency from 11.7 to $8.6 \mathrm{HZ}$ during the shakings in the longitudinal direction. This shift in frequency is not only because 
of decreased stiffness (due to cracking) but also due to inelastic rocking behavior of the piers. However, the frequency appears constant during the Wn (0.05), Taft $(0.2 \mathrm{~g})$ and Taft $(0.3 \mathrm{~g})$ excitations. This is in contrast with the damage and softening indicated by the time domain responses during these excitations. During the white noise test at the beginning, the damping was estimated to be $4.7 \%$ which increased to $10.3 \%$ with increasing level of damage during the following excitations.

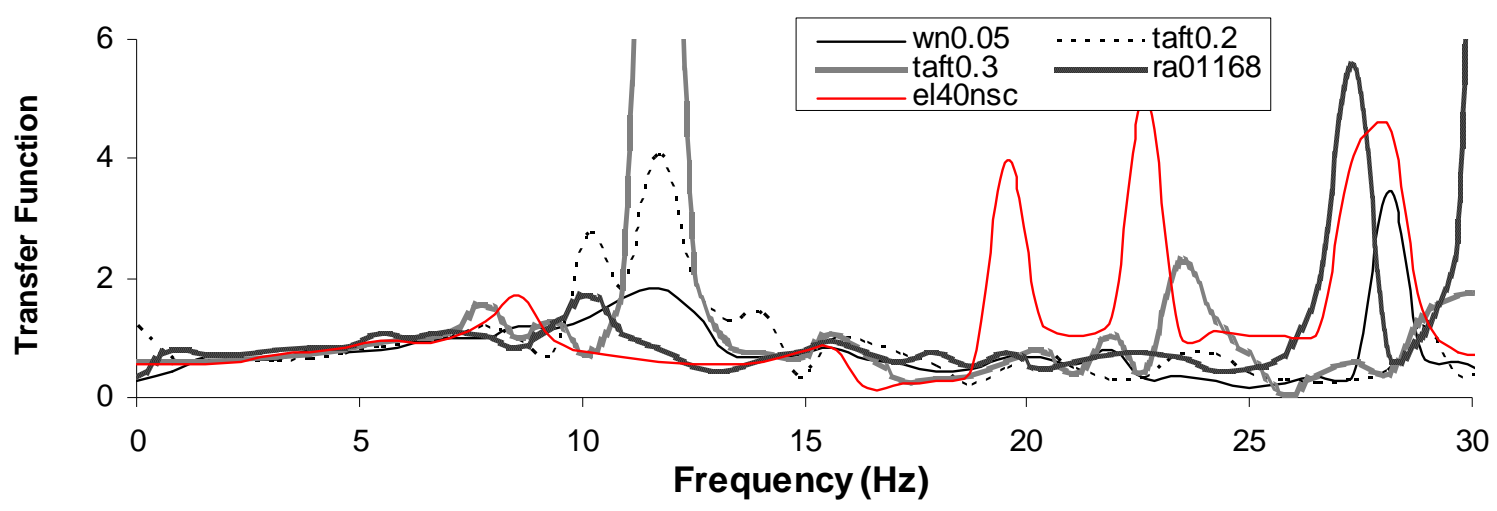

a) Longitudinal shaking

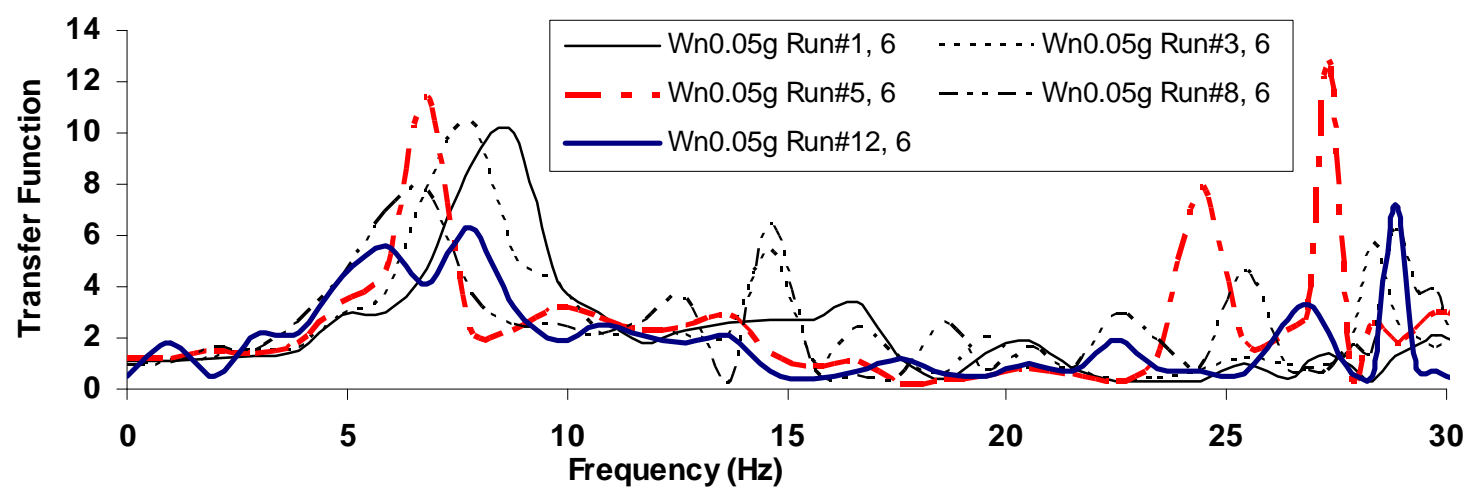

b) Transverse shaking

Figure 13: Transfer functions for the eaves level response acceleration

Table 5: Dynamic Characteristics of the Model (Longitudinal Shaking)

\begin{tabular}{|c|c|c|c|c|c|}
\hline Test & $\begin{array}{c}\text { Frequency } \\
f_{i}(\mathbf{H z})\end{array}$ & $\begin{array}{c}\text { Mode } \\
\text { shapes } \Phi_{i \mathrm{ij}}\end{array}$ & $\begin{array}{c}\text { Stiffness } \\
\left.K_{\mathrm{ij}} \mathrm{kN} / \mathrm{m}\right)\end{array}$ & $\begin{array}{c}\text { Intrinsic } \\
\text { damping } \xi_{\mathrm{i}}(\%)\end{array}$ & $\begin{array}{c}\text { Damping } \mathrm{C}_{\mathrm{ij}} \\
\text { (t rad/sec) }\end{array}$ \\
\hline $\mathrm{Wn}(0.02 \mathrm{~g})$ & (13.7) & $\left(\begin{array}{ll}1 & 0.82\end{array}\right)$ & (56922) & $(4.7)$ & (1324) \\
\hline $\mathrm{Wn}(0.05 \mathrm{~g})$ & (11.7) & $\left(\begin{array}{ll}1 & 0.81\end{array}\right)$ & (41516) & (3.0) & $(1130)$ \\
\hline Taft $(0.2 \mathrm{~g})$ & (11.7) & $\left(\begin{array}{ll}1 & 0.71\end{array}\right)$ & $(41516)$ & (4.6) & (1130) \\
\hline Taft $(0.3 \mathrm{~g})$ & (11.7) & $\left(\begin{array}{ll}1 & 0.8\end{array}\right)$ & $(41516)$ & (3.1) & (1130) \\
\hline RA01168 (0.5g) & (10.1) & $\left(\begin{array}{ll}1 & 0.93\end{array}\right)$ & (30937) & $(8.2)$ & (976) \\
\hline EL40NSC & (8.6) & $\left(\begin{array}{ll}1 & 0.91\end{array}\right)$ & $(22430)$ & $(10.3)$ & $(831)$ \\
\hline
\end{tabular}

Table 6: Dynamic Characteristics of the Model (Transverse Shaking)

\begin{tabular}{|c|c|c|c|c|c|}
\hline Test & $\begin{array}{c}\text { Frequency } \\
f_{\mathbf{i}}(\mathbf{H z})\end{array}$ & $\begin{array}{c}\text { Mode } \\
\text { shapes } \Phi_{\mathrm{ij}}\end{array}$ & $\begin{array}{c}\text { Stiffness } \\
\left.K_{\mathrm{ij}} \mathbf{k N} / \mathbf{m}\right)\end{array}$ & $\begin{array}{c}\text { Intrinsic } \\
\text { damping } \xi_{\mathrm{i}}(\%)\end{array}$ & $\begin{array}{c}\text { Damping } \mathrm{C}_{\mathrm{ij}} \\
(\mathrm{t} \mathrm{rad} / \mathrm{sec})\end{array}$ \\
\hline Wn $(0.05 \mathrm{~g})$ Run\#1 & $(9.8)$ & $\left(\begin{array}{ll}1 & 0.49\end{array}\right)$ & $(29733)$ & (8) & $(966)$ \\
\hline Wn $(0.05 \mathrm{~g})$ Run\#3 & $(8.8)$ & $\left(\begin{array}{ll}1 & 0.77\end{array}\right)$ & (23974) & (10) & $(867)$ \\
\hline Wn (0.05g) Run\#5 & $(7.8)$ & $\left.\begin{array}{ll}1 & 0.52\end{array}\right)$ & (18835) & (7) & (769) \\
\hline Wn (0.05g) Run\#8 & $(1$. & $\left(\begin{array}{ll}1 & 0.69\end{array}\right)$ & (18835) & $(14.5)$ & $(769)$ \\
\hline $\mathrm{Wn}(0.05 \mathrm{~g})$ Run\#12 & $(6.83)$ & $\left.\begin{array}{ll}1 & 0.79\end{array}\right)$ & (14442) & (20) & (673) \\
\hline
\end{tabular}


The frequency analysis was also performed for the most significant period of the white noise excitations in the transverse direction. The dynamic characteristics of the model and the damping calculated from the measurements during different transverse excitations are presented in Table 6. As can be seen in the Table, the fundamental frequency gradually reduced from $9.8 \mathrm{~Hz}$ to $6.8 \mathrm{~Hz}$ when measured after the model building had been exposed to excitations of increasing severity. A clear shift in fundamental frequency from 9.8 to about $6.0 \mathrm{~Hz}$ can also be observed in Figure 13b. Moreover, from the same figure it is also evident that the second mode frequency also reduced from $17 \mathrm{~Hz}$ to $14 \mathrm{~Hz}$ as the test progressed and the model softened. However, the second mode is not clearly defined in all excitations. The intrinsic damping was estimated to be $8 \%$ at the beginning of the test which increased gradually to $20 \%$ when the test was completed. Higher damping during the transverse shaking tests can be attributed to relatively severer damage during this test series.

\section{Discussion of Experimental Observations}

In contrast to the extent of damage observed to URM buildings during moderate earthquakes, the tested model building did not lose stability and integrity; neither did it show any sign of partial or total collapse even during severe excitations with PGA up to $0.8 \mathrm{~g}$. The possible reasons for the survival of the model can be a combination of the following:

1. Quality control: When fabricating the model building greater care was taken than is usually taken in real construction. Thus the overall strength of the brickwork was perhaps higher throughout the model than in most masonry buildings. In addition, as mentioned earlier, the mortar used in the model building was stronger than that in real URM buildings, which increased both the tensile and shearing strength of the walls and sometimes caused the cracks to traverse through the brick. Because of the stronger mortar, the piers could rock, and bond strength between the orthogonal walls increased. Farrowing of mortar is a common practice in URM wall construction. It leads to reduction in effective plan area of brickwork by more than $30 \%$. During the model construction, farrowing was not done; so the plan area was not reduced. It may have increased shearing capacity of the walls and piers (cohesion component).

2. Foundation: In contrast to real construction practice where most masonry buildings are constructed on loose and flexible URM foundation system, the model building was built on a reinforced foundation slab. The slab provided a rigid diaphragm at foundation level, thereby cutting down the effects of relative vertical and horizontal displacement of the foundation components due to soil movement. It facilitated much better distribution of stresses at the foundation level, which may have suppressed the distressing (and consequently the probable damage) of the superstructure.

3. Bond between orthogonal walls: The model building was constructed of full sized bricks with running bond. It led to a half-brick anchorage between orthogonal walls. If English bond had been used, the overlap (anchorage) between the orthogonal walls would have been a quarter-brick. Real URM buildings may therefore have a greater propensity to fail from out-of-plane effects.

4. Span to depth ratio of walls: In typical URM buildings with two wythe walls (wythe thickness $=110 \mathrm{~mm}$ ) with a cavity, the horizontal span to wall thickness ratio of the outof-plane walls would have been more than 50 and 35, respectively, for the transverse and longitudinal shakings. However, for the tested model building this ratio turned out to be 26 and 17 for the transverse and longitudinal shakings, respectively. This reduction in span to thickness ratio may have resulted in significant improvement in the out-of-plane stability of the face loaded walls.

5. Moment of Inertia: The use of single-wythe walls without scaling down the brick size would be able to accurately represent the in-plane stiffness and shear stress of double- 
wythe walls. However, because full-scale bricks were used for construction of the walls, consequent reduction in the out-of-plane moment of inertia would be just half, not $1 / 8$ as it would have been if half scale bricks were used. This disproportional change in moment of inertia might have given much higher out-of-plane flexural stiffness and strength to the walls.

6. Size effect: The sliding of the roof or the floor structure on the bearing walls during earthquakes is not uncommon in URM buildings. However, no significant relative displacement was observed between the floor/roof and the walls in the tested model building. It could be because of the additional load on the floor and the roof. The stresses were checked at the bottom of the walls to ensure global stress similitude. However, the local stresses (i.e. stresses at the bottom of joist or rafter at the supports) could not be in correct similitude. The additional weight on the floor and roof required for global similitude developed high frictional strength between the floor/roof diaphragm and the walls. This may have caused the hold down effect to suppress any significant relative movement between the floor/roof diaphragms and the bearing walls in contrast to the expected behaviour in a full scale prototype.

7. Diaphragm effects: To fix the weights to the floor and roof a lot of steel fittings were used. Furthermore, as the roof was constructed for portability and to carry 2 tonnes of additional weight it had to be strengthened. This made the roof and the floor structure stronger and stiffer. Due to high stiffness of the roof structure, the second storey out-ofplane walls moved as a rigid body causing damage to the walls at the ends of the wall plates when the model building was tested in transverse direction. During the tests in transverse direction, the roof diaphragm provided an alternative load path to transfer the imposed lateral load to the in-plane walls and therefore the out-of-plane walls survived even after extensive damage. Rattling marks between the roof purlins and the timber pieces at the eaves level were observed after dismantling the roof. This indicated that a lot of interaction was going on there.

8. Roof tiles behaviour: It is noteworthy that the roof tiles which were not tied up with the roof structure, scattered badly and few of them slid off the roof slope during the RA01168 $(0.5 \mathrm{~g})$ excitation. However, in real event these have been seen sliding off at much lower shaking. It could be because of a combination of the following probable reasons: (i) the tiles were not tied down (common in many parts of the world); (ii) the wires could have been corroded; (iii) roof could be more flexible; and (iv) the tiles were not laid well.

\section{Fragility curves for URM buildings}

To facilitate the occupancy of a building after an earthquake, buildings are tagged based on damage suffered by the building and its contents either in a colour-code or damagestate format as summarized in Table 7 . For the colour-code format, the level of damage to a building is assessed and a colour is tagged based on increasing severity of damage: green, yellow, orange, and red. For the damage-state format, buildings are assigned a damage state number from one to five based on the observed degree of damage to the building.

Table 7: Description of damage and post earthquake utility

\begin{tabular}{|l|l|l|}
\hline Details & Degree of damage & Post earthquake utility \\
\hline Tag colour & No damage, & building can be immediately occupied \\
\hline Green & Moderate damage & building can be entered to remove belongings \\
\hline Yellow & Heavy damage & $\begin{array}{l}\text { building can be entered for brief periods to remove } \\
\text { essential items only }\end{array}$ \\
\hline Orange & Near collapse/ collapse & building can not be entered \\
\hline Red &
\end{tabular}




\begin{tabular}{|l|l|l|}
\hline Damage state & \multicolumn{2}{|l|}{} \\
\hline 1 & None (pre-yielding) & Normal \\
\hline 2 & Minor/slight & Tolerable damage \\
\hline 3 & Moderate & Repairable damage \\
\hline 4 & Major/ extensive & Irreparable damage \\
\hline 5 & Complete collapse & Collapse \\
\hline
\end{tabular}

During the experiment, the level of damage suffered by the tested building was characterized according to the colour-code and damage-state format, and the measured displacements of the seismic mass centre at different damage levels were noted, as presented in Table 8. As these drift limits for different damage levels; both in terms of the colour-code and damage-state format, are decided based on engineering judgement, they have a degree of subjectivity and uncertainty. As shown in the Table, the model drifts are converted to the displacement of the seismic mass centre of the prototype URM building using the scale factor. Then, the peak ground acceleration (PGA) required to cause these levels of prototype displacements ( $\left.\Delta_{\text {Prototype }}\right)$ are calculated using the following relationship [22]:

$$
P G A=2 \pi \sqrt{\frac{C_{c} \Delta_{\text {Prototype }}}{g}} B_{\zeta} ; \quad P G A \geq 0.4 C_{c} B_{\zeta}
$$

where $\mathrm{C}_{\mathrm{c}}=$ base shear capacity and $B_{\zeta}$ is a damping related reduction factor given by [23]:

$$
B_{\zeta}=\sqrt{\frac{0.05+\zeta_{\text {eff }}}{0.1}}
$$

where $\varsigma_{\text {eff }}=$ effective viscous damping coefficient estimated as follows [22]:

$$
\varsigma_{\text {eff }}=0.05+\frac{2}{\pi} \eta\left(1-\frac{\Delta_{y}}{\Delta_{\max }}\right)
$$

where $\eta=$ efficiency factor taken here as $0.5, \Delta_{\mathrm{y}}=$ displacement at the first crack (from the test results, it is $0.7 \mathrm{~mm}$ and $1.05 \mathrm{~mm}$ for the longitudinal and transverse directions, respectively) and $\Delta_{\max }=$ maximum displacement at the seismic mass centre. The effective viscous damping predicted by Equation (4) includes the inherent damping in the system

\begin{tabular}{|c|c|c|c|c|c|c|c|}
\hline & Boundary & Drift limit & $\Delta_{\text {Model }}$ & $\zeta_{\text {effective }}$ & $\mathbf{B}_{\zeta}$ & $\Delta_{\text {Prototype }}$ & Expected PGA \\
\hline \multirow{3}{*}{ 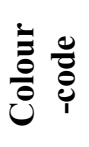 } & Green-Yellow & $0.1 \%$ & $2 \mathrm{~mm}$ & $20 \%$ & 1.58 & $4 \mathrm{~mm}$ & $0.35 \mathrm{~g}$ \\
\hline & Yellow-Orange & $0.4 \%$ & $8 \mathrm{~mm}$ & $33 \%$ & 1.95 & $16 \mathrm{~mm}$ & $0.43 \mathrm{~g}$ \\
\hline & Orange-Red & $0.8 \%$ & $16 \mathrm{~mm}$ & $35 \%$ & 2.00 & $32 \mathrm{~mm}$ & $0.53 \mathrm{~g}$ \\
\hline \multirow{4}{*}{ 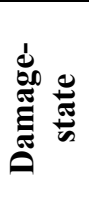 } & $1-2$ & $0.1 \%$ & $2 \mathrm{~mm}$ & $20 \%$ & 1.58 & $4 \mathrm{~mm}$ & $0.35 \mathrm{~g}$ \\
\hline & $2-3$ & $0.5 \%$ & $10 \mathrm{~mm}$ & $34 \%$ & 1.97 & $20 \mathrm{~mm}$ & $0.43 \mathrm{~g}$ \\
\hline & $3-4$ & $0.9 \%$ & $18 \mathrm{~mm}$ & $35 \%$ & 2.00 & $36 \mathrm{~mm}$ & $0.56 \mathrm{~g}$ \\
\hline & $4-5$ & $1.3 \%$ & $26 \mathrm{~mm}$ & $36 \%$ & 2.02 & $52 \mathrm{~mm}$ & $0.69 \mathrm{~g}$ \\
\hline
\end{tabular}
(assumed as $5 \%$ ) and the hysteretic damping estimated as $2 \eta / \pi\left(1-\Delta_{\mathrm{y}} / \Delta_{\max }\right)$.

Table 8: Drift limits and expected PGAs

The PGA calculated using Equation (2) and listed in Table 8 are the median values of the PGA corresponding to the boundaries between different damage levels; and these values are likely to vary due to the randomness in ground motion, uncertainty associated with the material properties, uncertainty in modelling and subjectivity in interpretation of the test results. It is common for the different randomness and uncertainties to be combined into a single parameter; i.e. the standard deviation [24]. It has been proved that the variation of 
demand (in fragility curves) normally confirms to a lognormal distribution [25]. The standard deviation of the log-normally distributed fragility curves (also called the dispersion factor) have been estimated as 0.5 for reinforced concrete [25] and 0.64 for masonry [26]. In this study, the lognormal standard deviation of the PGA functions for different damage states and colour tags is taken as 0.6 , which combined with the median PGA values shown in Table 8 are then used to develop fragility curves following a lognormal distribution.

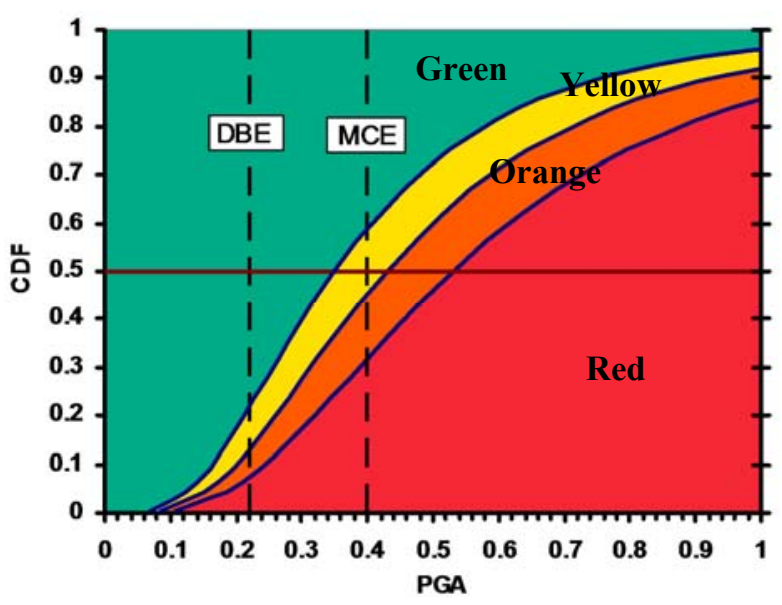

a) Colour-code fragility curves

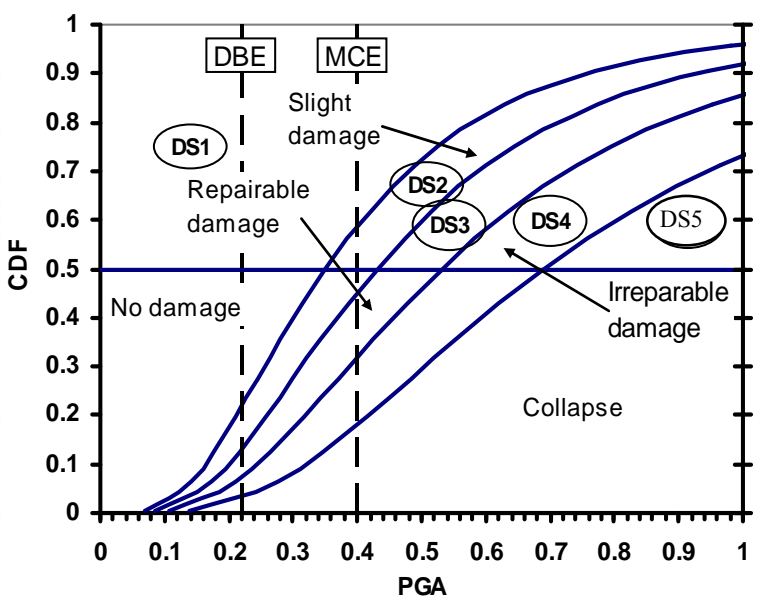

b) Damage-state fragility curves

Figure 14: Fragility curves for quantifying performance of two-storey URM buildings

Thus generated fragility curves for a typical URM house where damage states are classified according to the post-earthquake inspection-based colour-coding format as well as the damage-state format are presented in Figure 14. In the graph, MCE (Maximum Considered Earthquake) is the 2475 year return period event (i.e. $2 \%$ in 50 years) with PGA $=0.4 \mathrm{~g}$ and DBE (Design Basis Earthquake) is the 475 year return period event (i.e. $10 \%$ in 50 years) with PGA $=0.22 \mathrm{~g}$ on rock for Christchurch. It can be interpreted from the plot that if a DBE strikes Christchurch area, some $7 \%$ of the URM houses might be red tagged, $6 \%$ orange tagged, another $9 \%$ yellow tagged and the remaining $78 \%$ would be still inhabitable. However, if an MCE was to strike the city, some 31\% of the URM houses would be red tagged, $14 \%$ orange tagged, other $14 \%$ yellow tagged and only $31 \%$ would be inhabitable. Based on the damage-state considerations, if a DBE was to strike Christchurch, some $7 \%$ of the URM houses can be expected to suffer irreparable damage or collapse, while up to $93 \%$ may suffer damage that would be either slight or repairable. However, if an MCE was to strike, then some $32 \%$ URM houses might suffer irreparable damage or collapse with the remaining $68 \%$ suffering minor or repairable damage. Alarmingly, there is only about $68 \%$ chance that a URM building will maintain life-safety (i.e. by not exceeding Damage State 3 ) in an MCE. Note that the current fragility functions are generated based on the experiment of a URM building model with a strong reinforced foundation slab and the outcomes might be more alarming for URM buildings with loose and flexible foundation system.

\section{Conclusions}

A half-scale two-storey unreinforced brick masonry building with floor and roof structure is tested under longitudinal and transverse shakings. The experimental results indicate that in typical URM buildings, damage in in-plane walls is mostly concentrated in zones of high shear stress, notably the bottom storey. On the other hand, damage in the outof-plane walls is likely to occur mostly in zones of high response acceleration and starts from the top storey. The test indicated that rocking can lead to a stable non-linear response in both in-plane and out-of-plane directions provided that there is good bond between brick layers. 
Maintaining a good bond between orthogonal walls (and keeping the horizontal and vertical spans to acceptable levels) also suppresses the out-of-plane failure of the walls significantly.

The test results also reinforce that gable walls are the most vulnerable part of a URM building. The gable walls behave as unrestrained cantilevers and are likely to topple, which may be inhibited by securing the gable walls back into a roof diaphragm. It was also found that tying the roof tiles to the purlins greatly reduces the hazard that is inherent to the unsecured roof tiles during a seismic event. In the conducted tests unsecured tiles fell from the roof but tied roof tiles did not dislodge even under high response acceleration of up to $1.11 \mathrm{~g}$. Integrity and stiffness of diaphragms significantly improve the survival probability of URM buildings by redistributing lateral load through different load paths to the in-plane walls. It was found that after softening due to extensive cracking, the response of the model building was more or less constant regardless of the intensity of input motion. It indicates that the probability of URM buildings surviving a major shaking can be substantially improved by maintaining integrity.

Fragility curves for URM buildings are also generated both for colour-coded and damage-state formats based on the experimental observations. As expected, the fragility curves highlight the high seismic risk associated with URM houses. If the experimental fragility curves are used to assess safety of similar URM buildings in Christchurch area, in a design basis earthquake with $10 \%$ probability in 50 years some $7 \%$ of the URM houses are likely to suffer irreparable damage or collapse. Similarly, for an MCE (2\% in 50 years) some $32 \%$ of the URM houses in Christchurch are likely to suffer irreparable damage or collapse; potentially leading to loss of life.

\section{References}

1. Abrams DP, Shah N. Cyclic Load Testing of Unreinforced Masonry Walls. Advanced Construction Technology Centre Report No. 92-26-10: University of Illinois at UrbanaChampaign, Illinois, 1992.

2. Magenes G, Calvi GM. Shaking table tests on brick masonry walls. Proceedings of 10th European Conference on Earthquake Engineering 1995, Vienna, Austria; 3: 2419-2424.

3. Doherty KT. An Investigation of the Weak Links in the Seismic Load Path of Unreinforced Masonry Buildings. Ph D Thesis: Faculty of Engineering, University of Adelaide, Australia, 2000.

4. Griffith MC, Vaculik J, Lam TK, Wilson J, Lumntarna E. Cyclic testing of unreinforced walls in two-way bending. Earthquake Engineering and Structural Dynamics 2006; 36(6): 801-821.

5. Simsir C, Aschheim M, Abrams D. Influence of diaphragm flexibility on the out-of-plane response of unreinforced masonry bearing walls. 9th North American Masonry Conference 2002: Clemson, South Carolina, 2002.

6. Tomazevic M. Dynamic modelling of masonry buildings: storey mechanism as a simple alternative. Earthquake Engineering and Structural Dynamics 1987; 15(6): 731-749.

7. Qamaruddin M, Chandra B. Behaviour of unreinforced masonry buildings subjected to earthquakes. Professional Journal of Masonry Society of USA 1991; 9(12): 47-55.

8. Calvi GM, Pavese A. Application of dynamic identification techniques to a brick masonry building prototype. Proceedings of the 10th European Conference on Earthquake Engineering 1995, Vienna, Austria; 3: 2413-2418.

9. Tomazevic M. Seismic upgrading of old brick-masonry urban houses: tying of walls with steel ties. Earthquake Spectra 1996; 12(3): 599-622.

10. Costley AC, Abrams SP. Dynamic Response of Unreinforced Masonry Buildings with Flexible Diaphragm. Technical Report No. MCEER-96-0001: MCEER, USA, 1996. 
11. Benedetti D, Carydis P, Pezzoli P. Shaking table test on 24 masonry buildings. Earthquake Engineering and Structural Dynamics 1998; 27: 67-90.

12. Yi T, Moon F L, Leon RT, Kahn LF. Lateral load tests on a two-story unreinforced masonry building. ASCE Journal of Structural Engineering 2006; 132(5): 643-652.

13. Bothara JK, Bishnu P, Guragain R. Seismic retrofitting of low strength unreinforced masonry non-engineered school buildings. Bulletin of the New Zealand Society for Earthquake Engineering 2004; 37(1): 13-22.

14. Bothara JK, Shrestha H. How buildings behaved during 26 December 2003 earthquake in Bam? Journal of the Institute of Engineering, Kathmandu 2004; 4(1): 63-71.

15. Bothara JK, Hicyilmaz KMO. General observations of building behaviour during the $8^{\text {th }}$ October 2005 Pakistan Earthquake. Bulletin of the New Zealand Society for Earthquake Engineering 2008; 41 (4): 209-233.

16. Bothara JK. A Shaking Table Investigation on the Seismic Resistance of a Brick Masonry House. Masters Thesis: University of Canterbury, New Zealand, 2004.

17. Bradley BA, Dhakal RP, Mander JB, Li L. Experimental multi-level seismic performance assessment of 3D RC frame designed for damage avoidance. Earthquake Engineering and Structural Dynamics 2008; 37(1): 1-20.

18. Dhakal RP, Mander JB, Mashiko N. Identification of critical ground motions for seismic performance assessment of structures. Earthquake Engineering and Structural Dynamics 2006; 35(8): 989-1008.

19. Iwan WD, Peng CY. An identification methodology for a class of hysteretic structures. Earthquake Engineering and Structural Dynamics 1992; 21: 695-712.

20. Bruneau M. State-of-the-art report on seismic performance of unreinforced masonry buildings. ASCE Journal of Structural Engineering 1994; 120(1): 230-251.

21. Bracci JM, Reinhorn AM, Mander JB. Seismic Resistance of Reinforced Concrete Frame Structures Designed only for Gravity, Part I: Design and Properties of One-third Scale Model Structure. Technical Report MCEER-92-0027: MCEER, USA, 1992.

22. Pekcan G, Mander JB, Chen SS. Fundamental Considerations for the Design of Nonlinear Viscous Dampers. Earthquake engineering and Structural Dynamics 1999; 28: 1405-1425.

23. Martinez ME. Performance-based Seismic Design and Probabilistic Assessment of Reinforce Concrete Moment Resisting Frame Structure, Masters' Thesis 2002, University of Canterbury, Christchurch, New Zealand.

24. Cornell CA, Fatemeh JF, Hamburger RO, Foutch DA. Probabilistic basis for 2000 SAC federal emergency management agency steel moment frame guidelines. Journal of Structural Engineering 2002; 128(4): 526-533.

25. Mander JB, Dhakal RP, Mashiko N, Solberg K. Incremental dynamic analysis applied to seismic financial risk assessment of bridges. Engineering Structures 2007; 29(10): 26622672.

26. Texas Department of Public Safety. BC Case Study: Earthquake Structural Retrofit Report. 2003. "http://www.txdps.state.tx.us/dem/mitigationbca/CASE STUDIES/2003 Case Studies/BC Case Study - Earthquake Structural Retrofit.doc” Assessed 3 April 2009. 